\title{
Bridge helix of Cas9 modulates target DNA cleavage and mismatch tolerance
}

Kesavan Babu, ${ }^{\dagger}$ Nadia Amrani, ${ }^{*}$ Wei Jiang ${ }^{\S}$ S.D. Yogesha,${ }^{\dagger / /}$ Richard Nguyen, ${ }^{\dagger, \perp}$ Peter Z. Qin, ${ }^{\S}$ Rakhi Rajan ${ }^{* \dagger}$

Department of Chemistry and Biochemistry, Price Family Foundation Institute of Structural Biology, Stephenson Life Sciences Research Center, University of Oklahoma, 101 Stephenson Parkway, Norman, OK, 73019, USA

\# RNA Therapeutics Institute, University of Massachusetts Medical School, 368 Plantation Street, Sherman Center, AS5.2007, Worcester MA 01605, USA

$\S$

Department of Chemistry, University of Southern California, 3430 S. Vermont Ave., Los Angeles, CA, 90089, USA ${ }^{1}$

$\|$

Current Address: Krystal Biotech, Inc. 2100 Wharton Street, Suite 701 Pittsburgh, PA

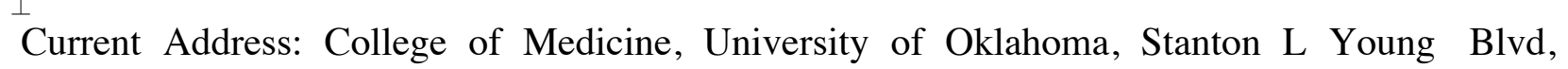
Oklahoma City, OK 73117

*Correspondence: r-rajan@ou.edu

SUPPLEMENTARY DATA

Supplementary Methods

Supplementary Figures S1-S16

Supplementary Tables S1-S8

Supplementary References 


\section{SUPPLEMENTARY METHODS}

\section{SM 1. Protein purification}

Purification protocol was followed as reported previously. ${ }^{l}$ The cells were grown in 2XYT medium at $37^{\circ} \mathrm{C}$ till optical density (OD) 600 reached around 0.8 to 1 and induced with $0.2 \mathrm{mM}$ IPTG. The cells were incubated at $18^{\circ} \mathrm{C}$ for $12-16$ hours. After incubation, cells were pelleted and re-suspended in buffer A (50 mM TRIS pH 8, $500 \mathrm{mM} \mathrm{NaCl,} 5 \mathrm{mM}$ imidazole, 1 $\mathrm{mM}$ TCEP) for Ni-NTA chromatography. Protease inhibitors [Pepstatin $(1 \mu \mathrm{g} / \mathrm{mL})$, Leupeptin $(1 \mu \mathrm{g} / \mathrm{mL})$, Benzimidine $(1 \mathrm{mM})$, PMSF $(1 \mathrm{mM})]$ were added to thawed cells and lysed using a sonicator at 35 Amplitude, $3 \mathrm{sec}$ on, $20 \mathrm{sec}$ off, for a total of 3 minutes. The lysate was spun at $18,000 \mathrm{rpm}$ for 45 minutes, filtered using $0.2 \mu$ filter and loaded onto Ni-NTA column and the fractions were eluted using a continuous gradient elution with buffer B (50 mM TRIS pH 8, 500 $\mathrm{mM} \mathrm{NaCl}, 500 \mathrm{mM}$ imidazole, $1 \mathrm{mM}$ TCEP). SpyCas9 protein fractions were pooled followed by the addition of TEV protease to remove the MBP tag. The cleavage occurred at $4^{\circ} \mathrm{C}$ concurrently with an overnight dialysis into the Cation exchange column (SP HP) equilibration buffer (20 mM HEPES pH 7.5, 150 mM KCl, 2 mM DTT, 10\% glycerol). After dialysis, sample was loaded on to the equilibrated SP HP column and the protein was eluted with a continuous salt gradient using elution buffer (20 mM HEPES pH 7.5, $1 \mathrm{M} \mathrm{KCl,} 2 \mathrm{mM}$ DTT, $10 \%$ glycerol). Fractions were pooled and concentrated to around 1-2 mL for loading into an equilibrated S300 column and eluted using the buffer (20 mM HEPES pH 7.5, $150 \mathrm{mM} \mathrm{KCl,} 2 \mathrm{mM}$ TCEP). Pure fractions were pooled and concentrated using an amicon 30-kDa concentrator. The concentration of the protein was measured using a nano-drop by monitoring the absorbance at $280 \mathrm{~nm}$. The protein was aliquoted, frozen using liquid nitrogen, and stored at $-80^{\circ} \mathrm{C}$.

\section{SM 2. RNA transcription}

The transcription reaction $(200 \mu \mathrm{L})$ was carried out for 4 hours at $37^{\circ} \mathrm{C}$ and contained 
transcription buffer (40 mM TRIS-HCl pH 8.0, 1 mM Spermidine, $50 \mu \mathrm{g}$ BSA, 20 mM MgCl, 2 mM DTT), nucleotide triphosphates (6 mM GTP, $5 \mathrm{mM} \mathrm{UTP,} 5 \mathrm{mM}$ ATP and $5 \mathrm{mM} \mathrm{CTP}$ ), $3 \mu \mathrm{g}$ linearized template, $50 \mu \mathrm{g}$ of RNasin, $1 \mu \mathrm{g}$ inorganic pyrophosphatase, and $40 \mu \mathrm{g}$ of T7 RNA polymerase. ${ }^{2,3}$ Transcribed RNA was precipitated by adding cold $100 \%$ ethanol, followed by storage overnight at $-20^{\circ} \mathrm{C}$. RNA pellet was washed with $80 \%$ ethanol and purified by gel extraction from a denaturing acrylamide gel containing $8 \mathrm{M}$ urea. RNA pellet following the gel extraction was dissolved in RNase-free water.

\section{SM 3. Measurement of the rate of substrate cleavage}

Reaction mixtures of DNA plasmid substrate (100 ng) and Cas9 protein-RNA effector complex (50 $\mathrm{nM})$ were assembled as described in Materials and Methods in the main text. Reactions were carried out at $37^{\circ} \mathrm{C}$ at various time-points (15 seconds to 60 minutes) and the products were resolved on $1 \%$ agarose gels to determine the "Total Activity" (i.e., "TA(\%)", equation 1 , main text) as described. The amount of precursor remained (Frac[P]) was computed as:

$$
\operatorname{Frac}[\mathrm{P}]=1-\left(\frac{T A(\%)}{100}\right)
$$

The average Frac $[\mathrm{P}]$ from three replications and SEM were used for time dependence studies.

The time-dependence of $\operatorname{Frac}[\mathrm{P}]$ were fit to the following equation using the program Kaleidagraph (Synergy, PA):

$$
\operatorname{Frac}[\mathrm{P}]=(1-a)+a \cdot \exp \left(-k_{o b s} \cdot t\right)
$$

where $\mathrm{t}$ is time, $k_{o b s}$ is the rate of loss of the substrate precursor, and a is the total fraction of substrate cleaved. 


\section{SUPPLEMENTARY FIGURES}

\section{Figure S1}

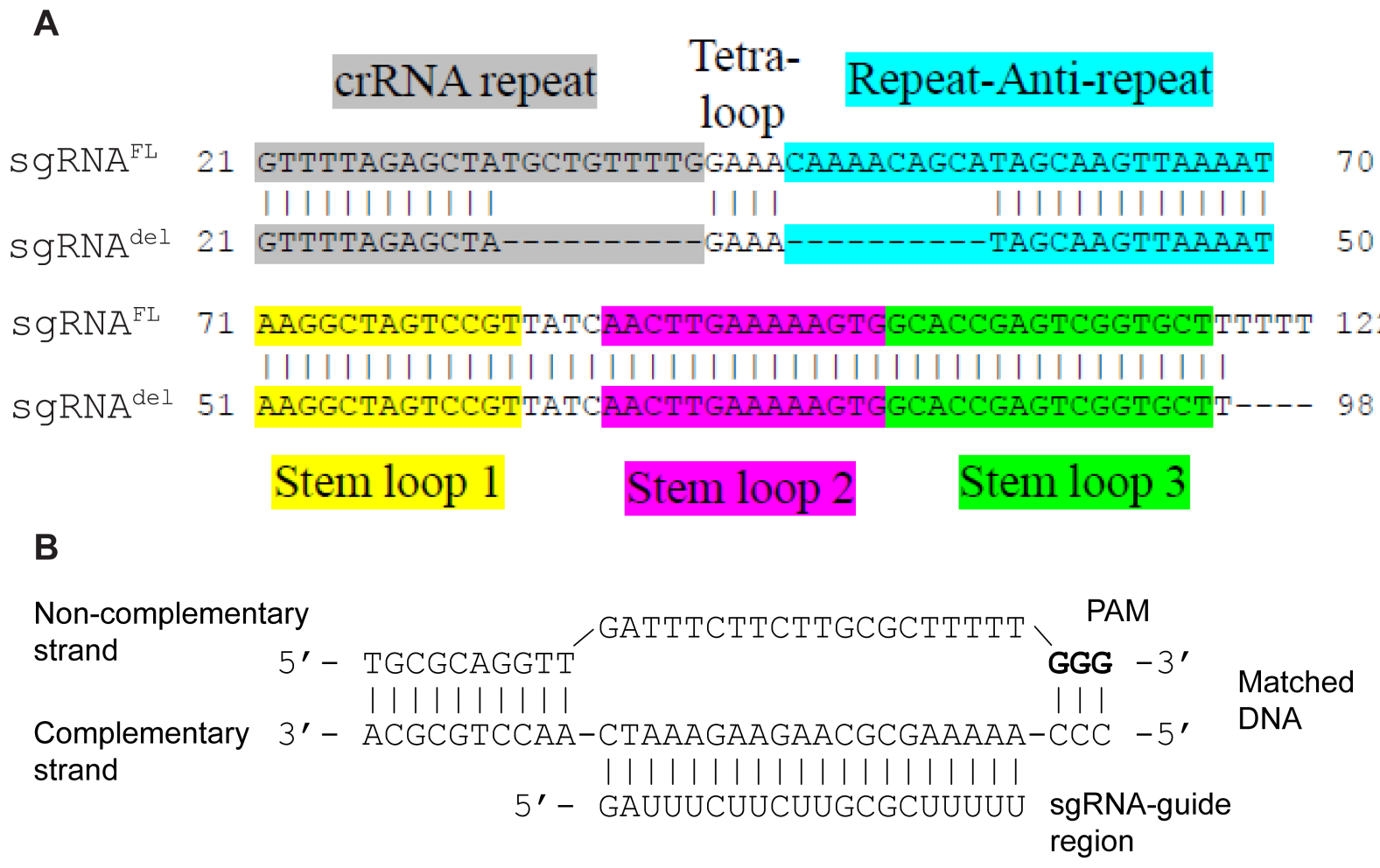

Figure S1. sgRNA sequences used in the study. A) Alignment of $\operatorname{sgRNA}{ }^{\mathrm{FL}}$ and $\operatorname{sgRNA} \mathrm{A}^{\mathrm{del}}$ used in the experiments. The guide region (20 nt) is not shown in the alignment. B) Schematic representation of protospacer fully complementary (matched DNA) to the guide sequence of sgRNA. PAM region is shown in bold. 
Figure S2

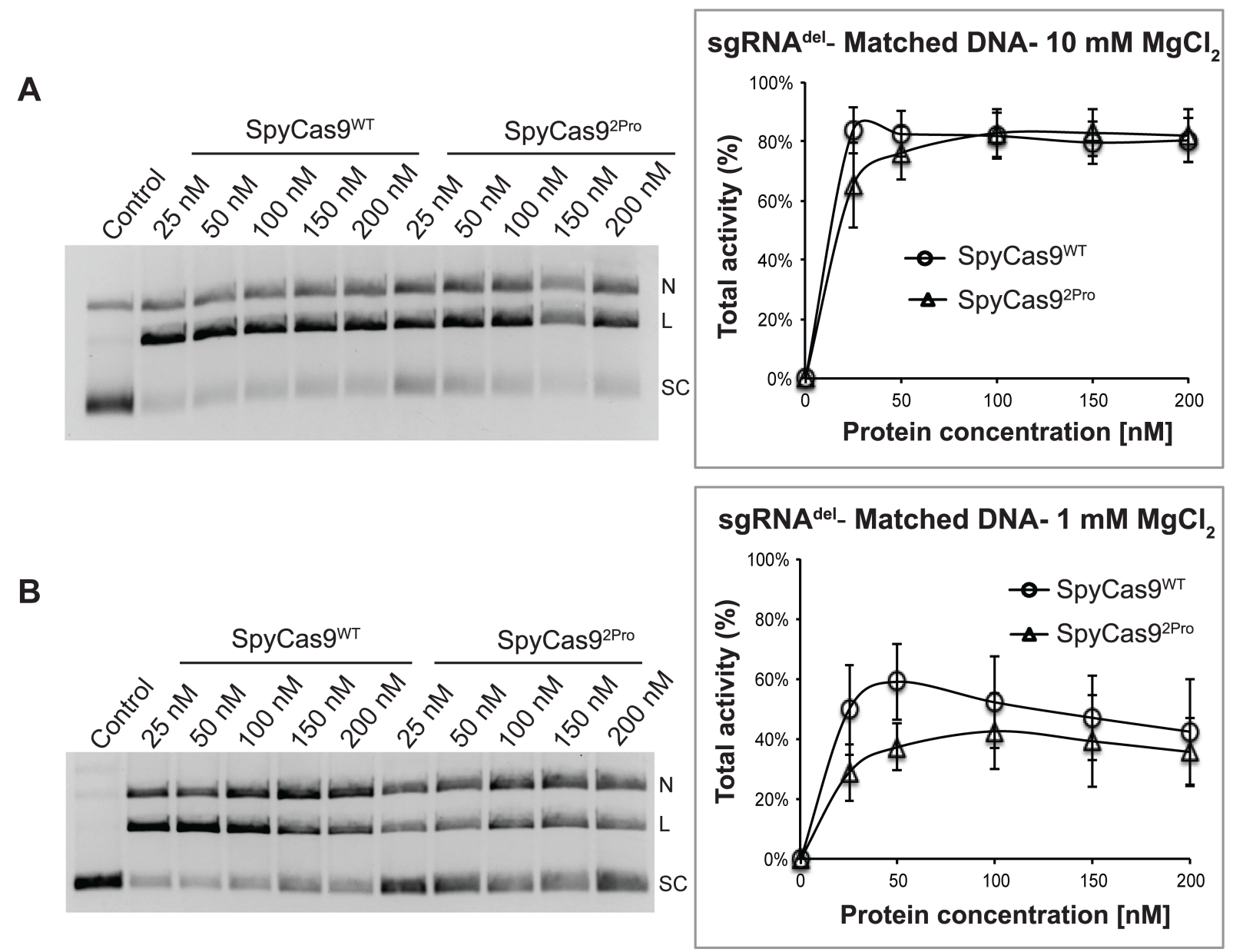

Figure S2. Comparison of SpCas9 ${ }^{\mathrm{WT}}$ and $\operatorname{SpCas}^{2 \mathrm{2Pro}}$ activities using sgRNA ${ }^{\text {del }}$ and wild-type substrate (matched DNA). A) Activity with increasing protein: sgRNA ${ }^{\text {del }}$ complex at $10 \mathrm{mM}$ $\mathrm{Mg}^{2+}$ ions. B) Activity with increasing protein: $\mathrm{sgRNA}^{\text {del }}$ complex at $1 \mathrm{mM} \mathrm{Mg}^{2+}$ ions. Average total activities from three replications are shown, with error bars representing SEM. 


\section{Figure S3}

A

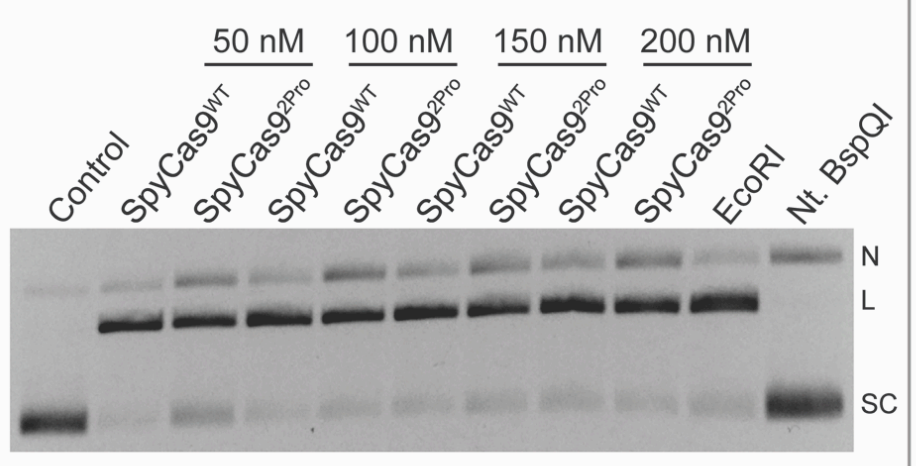

B

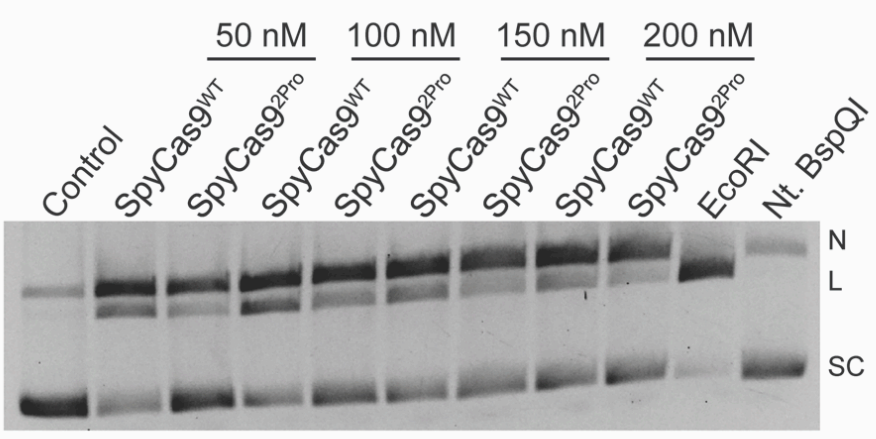

sgRNA ${ }^{\mathrm{FL}}$ - Matched DNA- $10 \mathrm{mM} \mathrm{MgCl}_{2}$

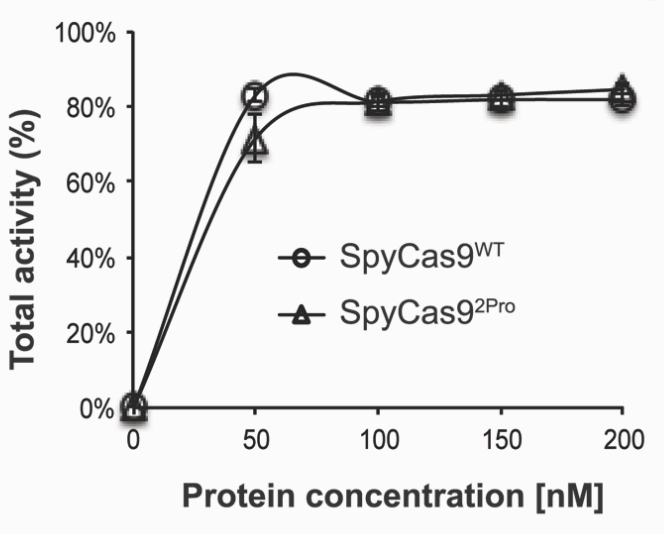

sgRNA ${ }^{\mathrm{FL}}$ - Matched DNA- $1 \mathrm{mM} \mathrm{MgCl}_{2}$

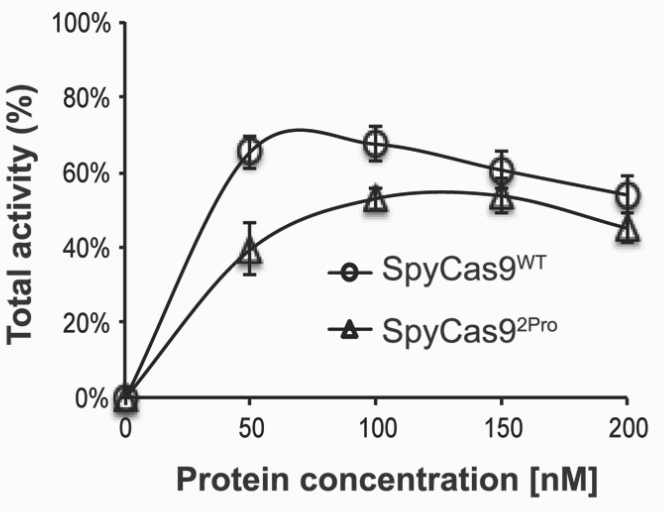

Figure S3. Comparison of SpyCas $9^{\mathrm{WT}}$ and SpyCas $9^{2 \mathrm{Pro}}$ activities using $\operatorname{sgRNA}{ }^{\mathrm{FL}}$ and wildtype substrate (matched DNA). A) Activity with increasing protein: $\operatorname{sgRNA}^{\mathrm{FL}}$ complex at 10 $\mathrm{mM} \mathrm{Mg}{ }^{2+}$ ions. B) Activity with increasing protein: $\mathrm{sgRNA}^{\mathrm{FL}}$ complex at $1 \mathrm{mM} \mathrm{Mg}^{2+}$ ions. Average total activities from three replications are shown, with error bars representing SEM. 
Figure S4

$\mathbf{A}$

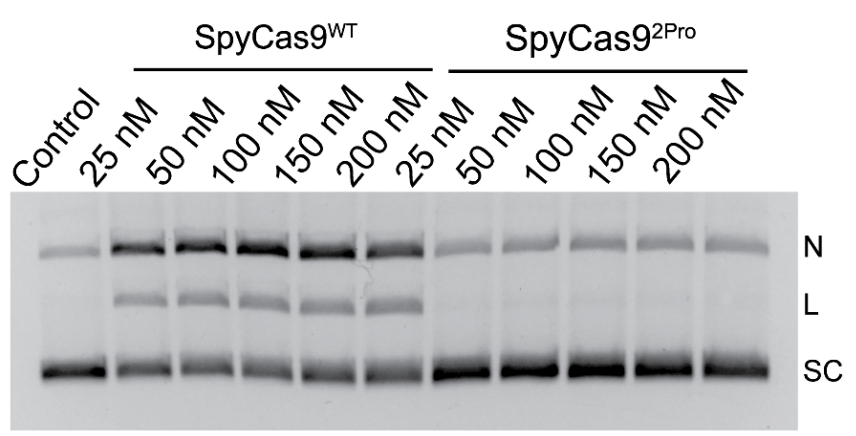

B

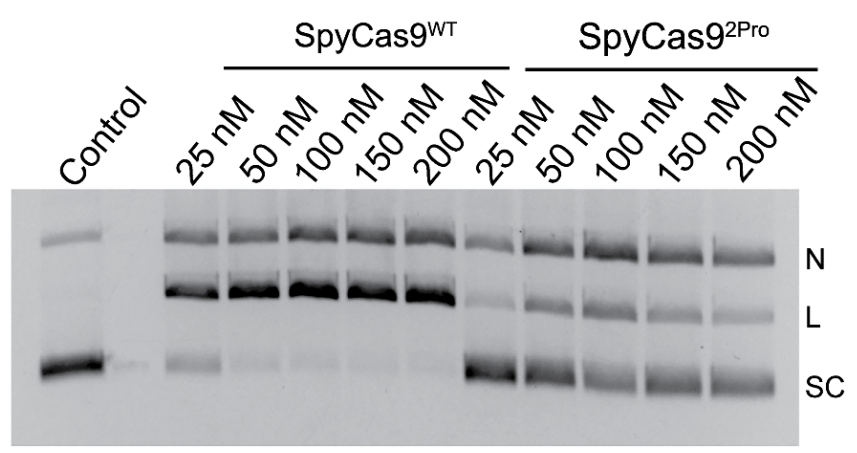

\section{sgRNA del- MM5 DNA- 1 mM $\mathrm{MgCl}_{2}$}
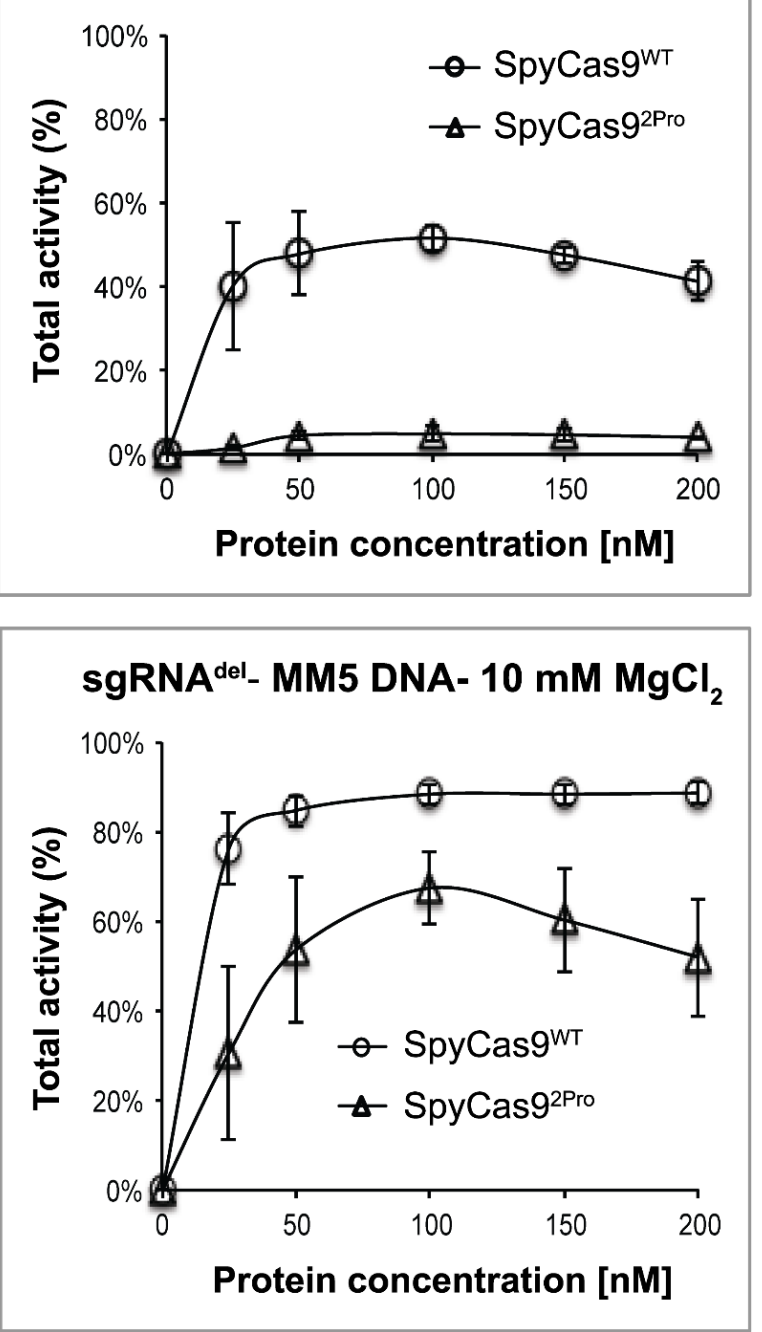

Figure S4. Comparison of SpyCas9 ${ }^{\mathrm{WT}}$ and SpyCas9 $9^{2 \mathrm{Pro}}$ activities using mismatched substrate and sgRNA ${ }^{\text {del }}$. A) Activity with MM5 (mismatch at $5^{\text {th }}$ position of the PAM proximal side) at $1 \mathrm{mM} \mathrm{Mg}^{2+}$ ions. B) Activity with MM5 at $10 \mathrm{mM} \mathrm{Mg}{ }^{2+}$ ions. Average total activities from three replications are shown, with error bars representing SEM. 
Figure S5

A

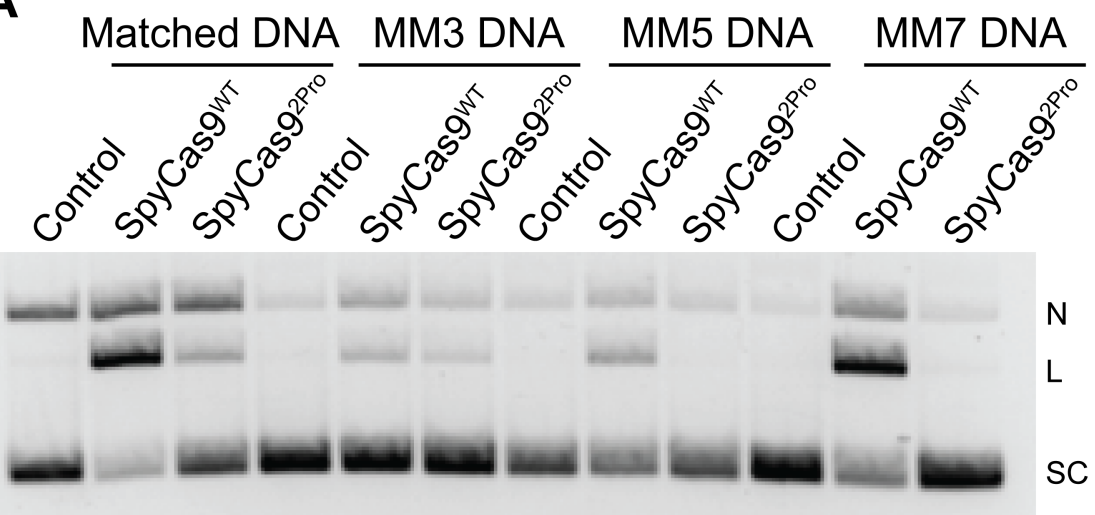

B

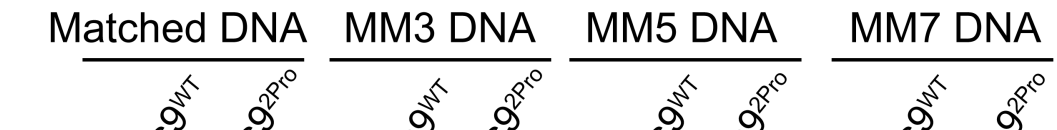
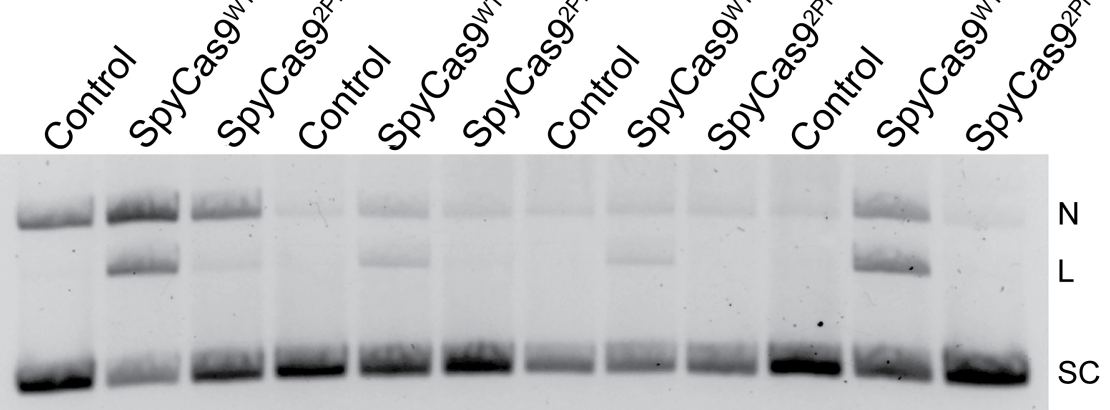

Figure S5. Representative gels showing DNA cleavage activity of SpyCas9 ${ }^{\mathrm{WT}}$ and SpyCas9 ${ }^{2 P r o}$ using PAM proximal single mismatched substrates and sgRNA ${ }^{\text {del }}$ at 5 mM (A) and $1 \mathrm{mM}(\mathrm{B}) \mathbf{M g}^{2+}$ ions. The single mismatches include MM3, MM5 and MM7. Supercoiled (SC), linear (L), and nicked (N) DNA bands are indicated. 
Figure S6
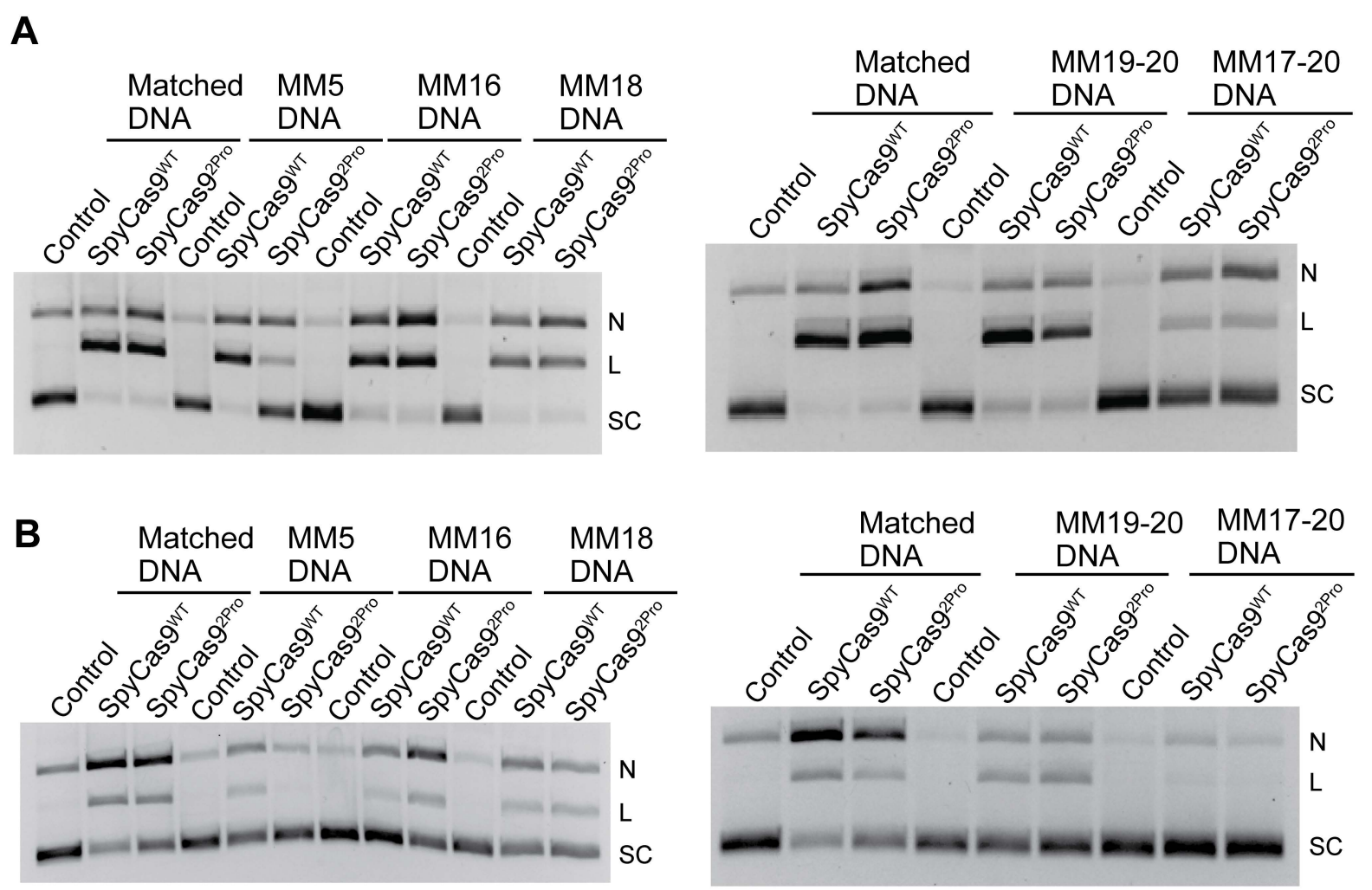

Figure S6. Representative gels showing DNA cleavage activity of SpyCas9 ${ }^{\mathrm{WT}}$ and SpyCas9 ${ }^{2 P r o}$ using substrates with PAM-distal mismatches and sgRNA $^{\text {del }}$. A) Activity at 5 $\mathrm{mM} \mathrm{MgCl}$. B) Activity at $1 \mathrm{mM} \mathrm{MgCl} \mathrm{M}_{2}$. MM5 is shown as a control for activity reduction with a PAM-proximal mismatch. [Supercoiled (SC), linear (L), and nicked (N) DNA]. 


\section{Figure S7}

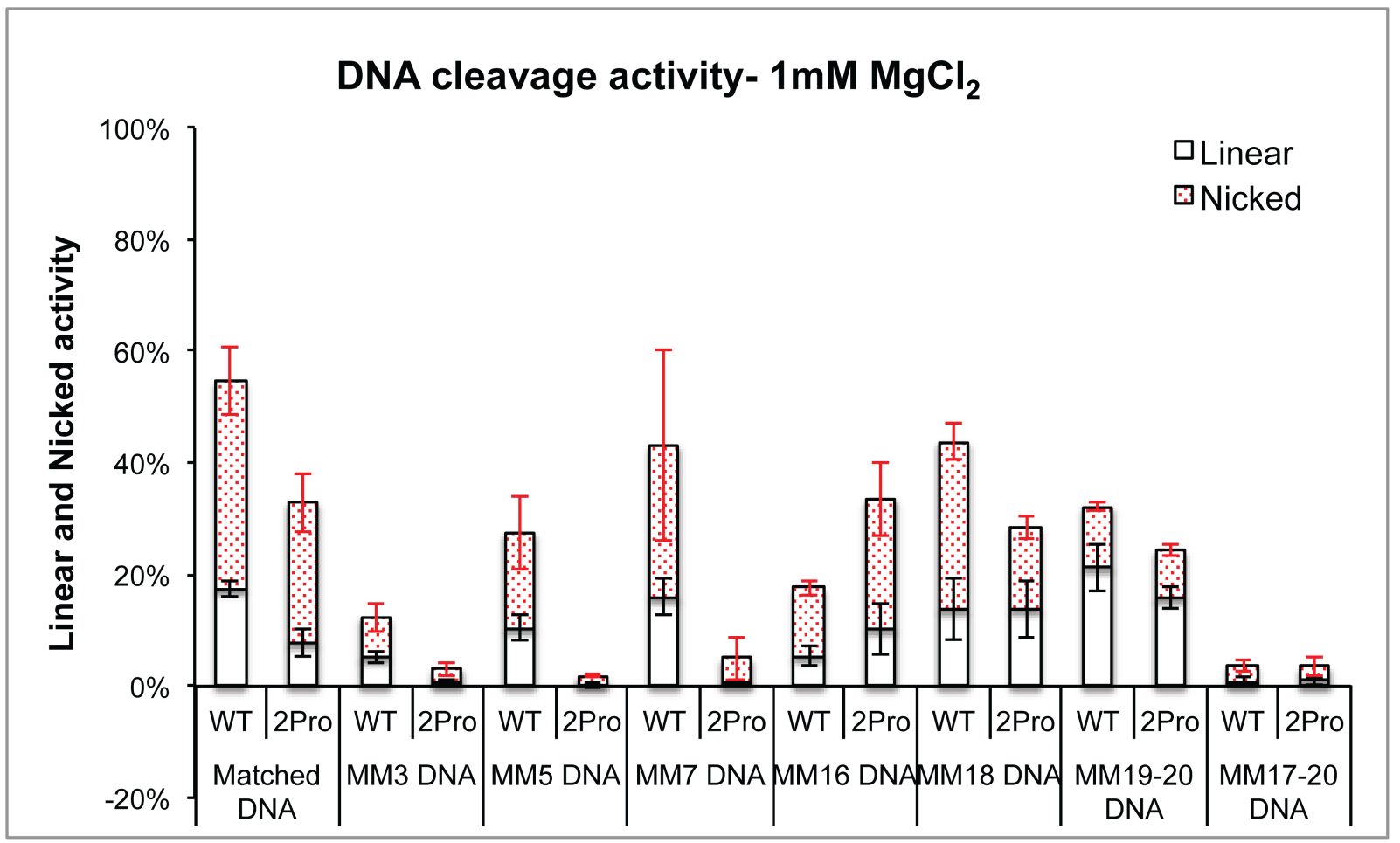

Figure S7. Comparison of SpyCas9 ${ }^{\mathrm{WT}}$ and SpyCas9 $9^{2 \mathrm{Pro}}$ activities using different mismatched substrates and $\operatorname{sgRNA}{ }^{\text {del }}$ at $1 \mathbf{m M ~ M g}^{2+}$ ions. Graph shows the total activity with separate regions indicating the percentage of nicked (red shaded regions) and linear products. The enzyme concentration was at $50 \mathrm{nM}$. For matched DNA and MM5 DNA, there are nine and six different replications respectively, while for the rest there are three replications. Error bars represent SEM. 
Figure S8
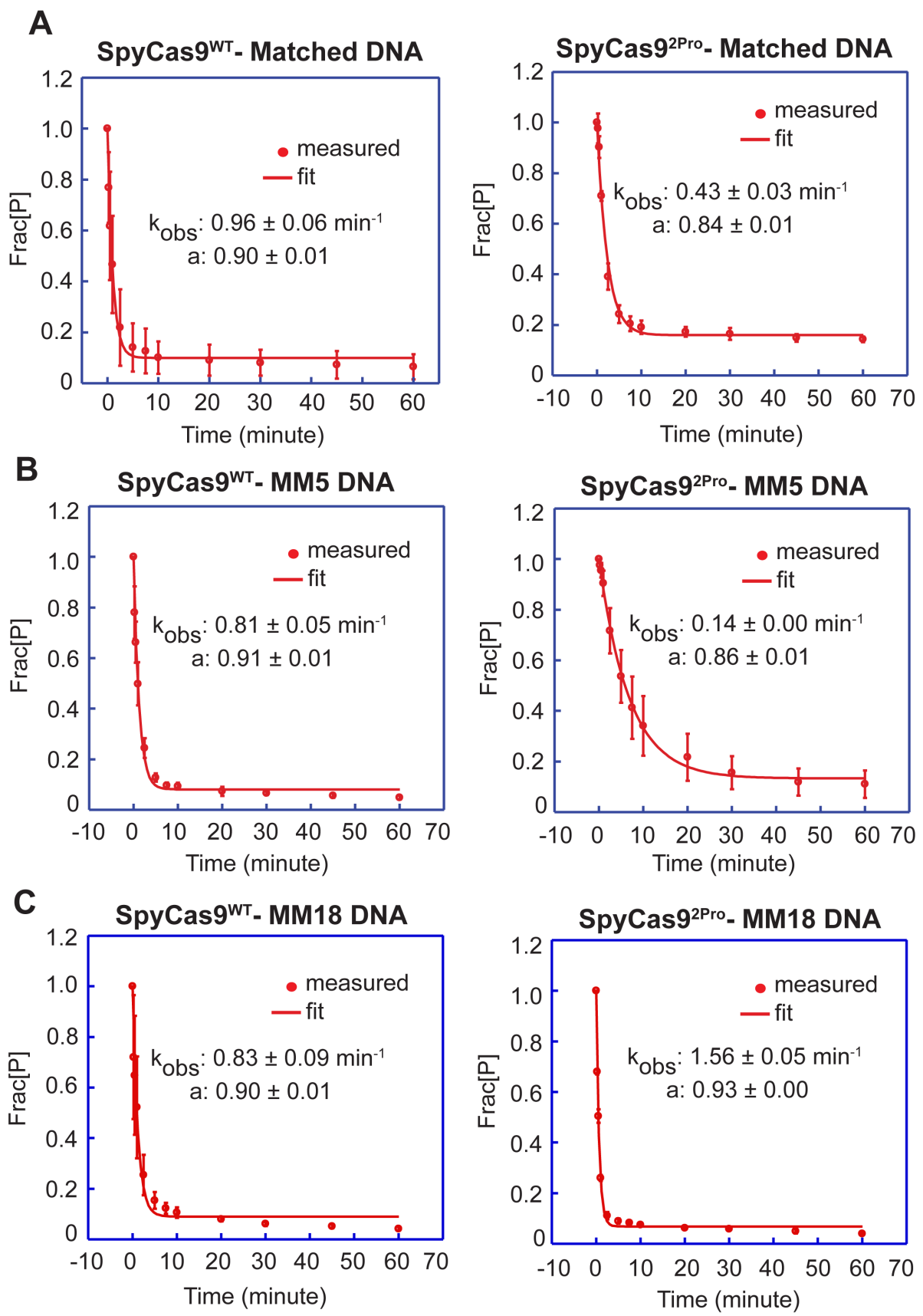

Figure S8. Measurements of DNA cleavage rates. Values of $\mathrm{k}_{\mathrm{obs}}$ and active fraction obtained from fitting the time course data (see Supplemental Method, SM 3) are shown for each panel, with the error values representing the error of fitting. Frac $[\mathrm{P}]$ represents the amount of precursor remaining. As expected, SpyCas $9^{\mathrm{WT}}$ has reduced rate of cleavage on mismatched DNAs. For SpyCas $9^{2 \text { Pro }}$, the effects vary depending on the locations of the mismatch, indicating that the proline substitution in the BH-loop affects multiple aspects of Cas9 function. 
Figure S9

A

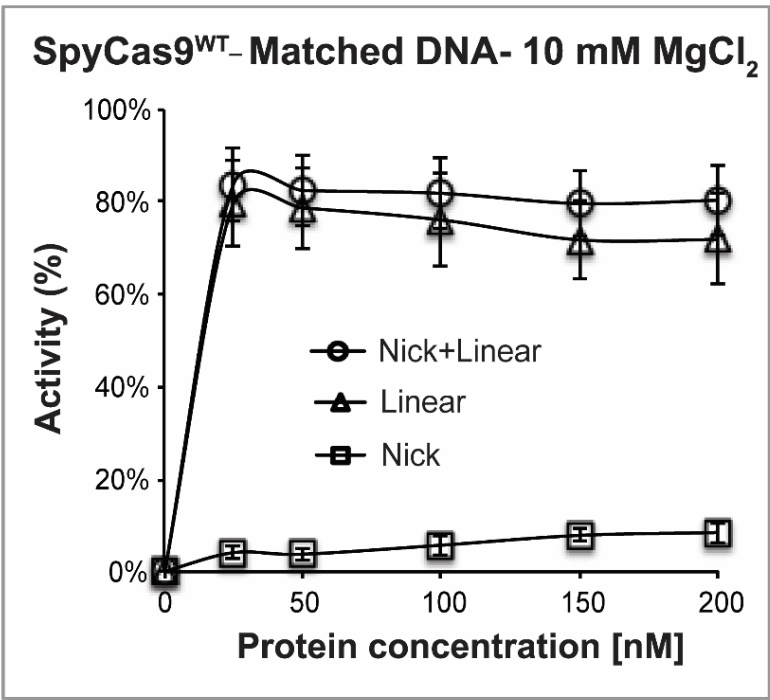

SpyCas92Pro-Matched DNA- $10 \mathrm{mM} \mathrm{MgCl}$

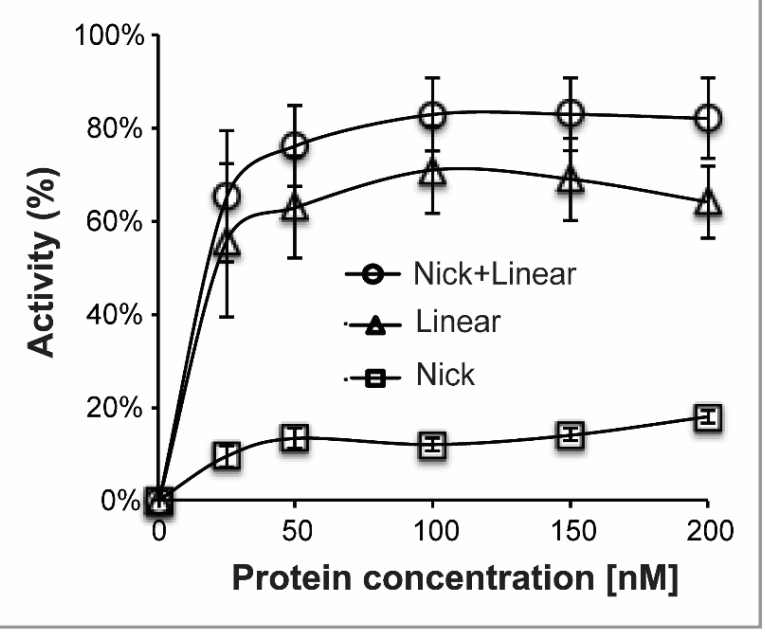

B

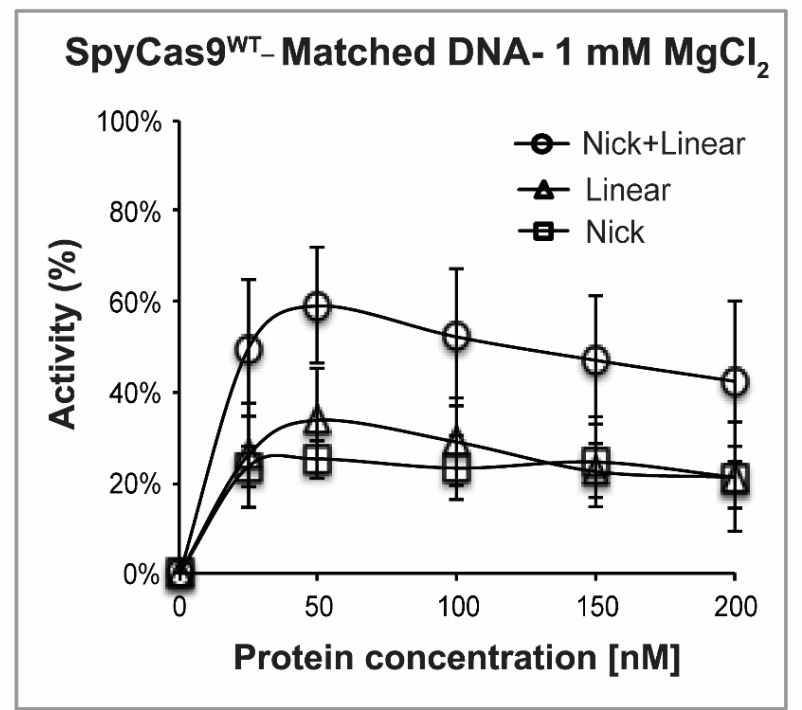

SpyCas92Pro-Matched DNA- 1 mM $\mathrm{MgCl}_{2}$

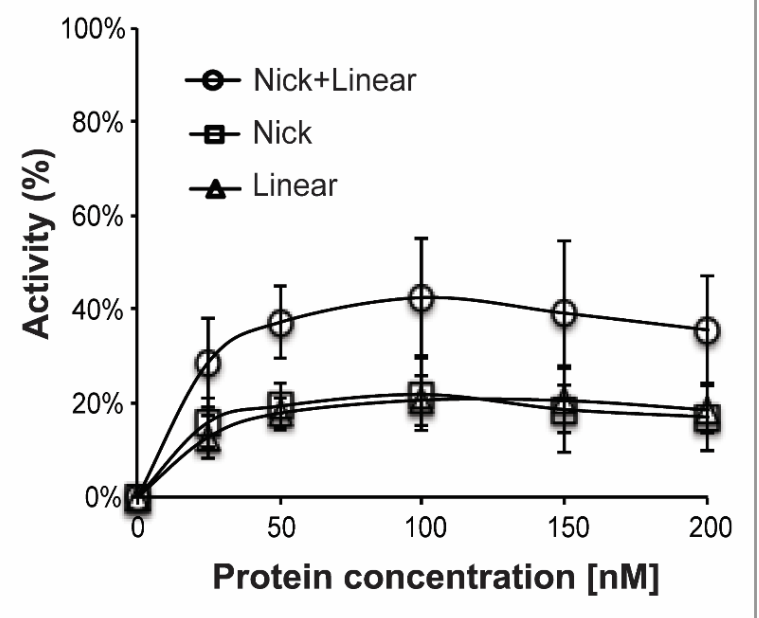

Figure S9. Comparison of cleavage patterns of $\operatorname{SpyCas9}^{\mathrm{WT}}$ and $\mathrm{SpyCas} 9^{2 \mathrm{Pro}}$ proteins on matched DNA using $\mathbf{s g R N A}{ }^{\text {del }}$. A) Activity at $10 \mathrm{mM} \mathrm{Mg}^{2+}$ ions and a fully matched DNA

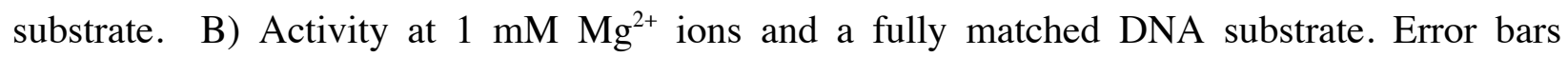
represent SEM calculated based on three replications. 
Figure S10

A
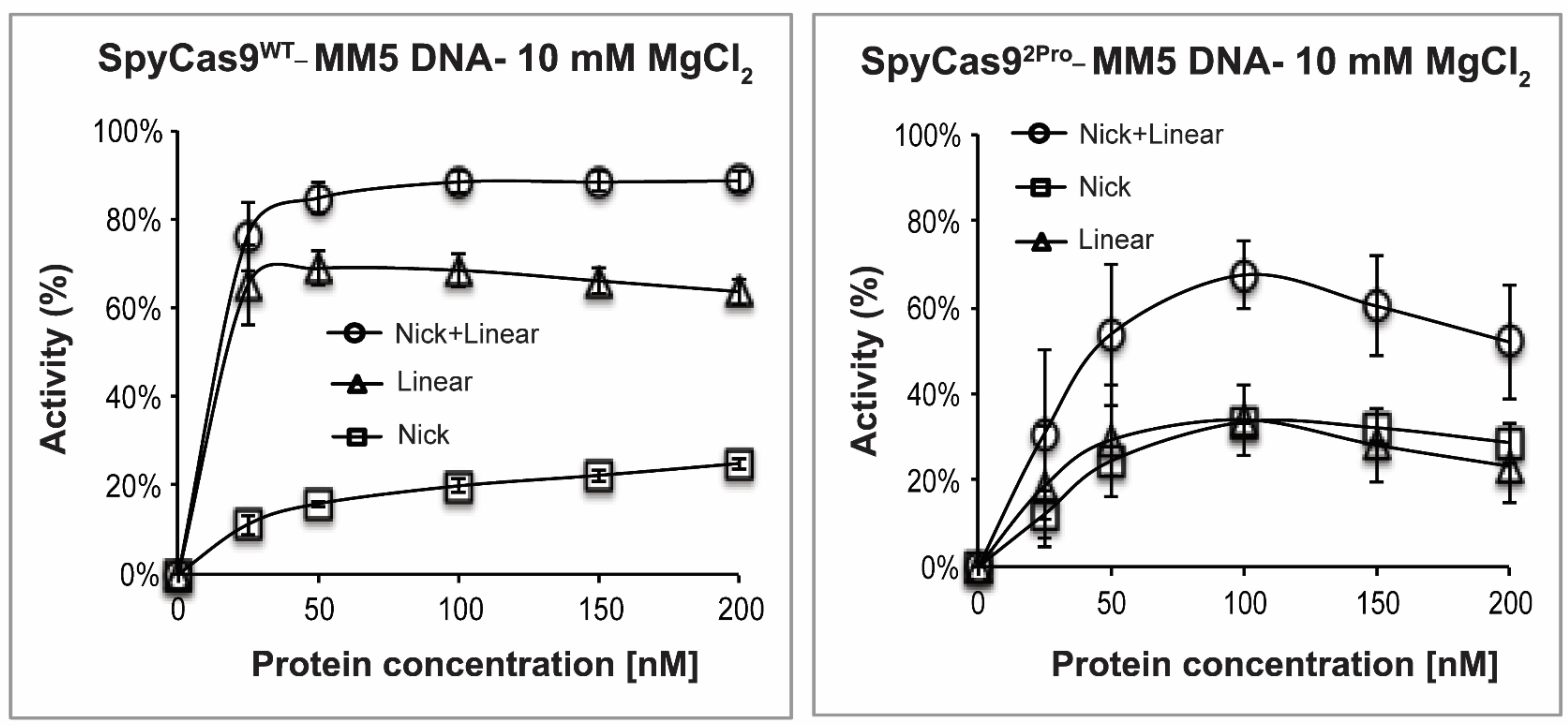

B

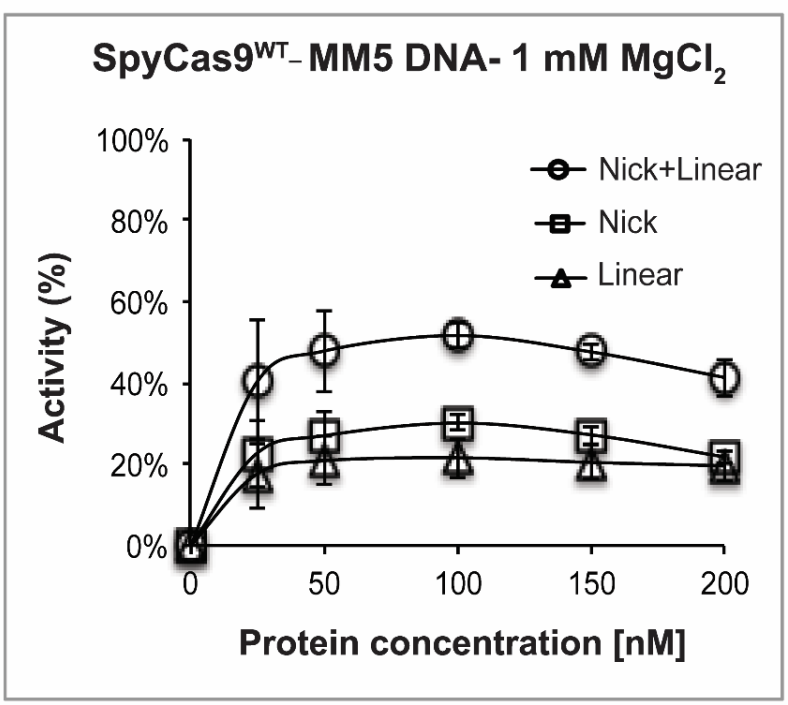

SpyCas92Pro-MM5 DNA- 1 mM MgCl

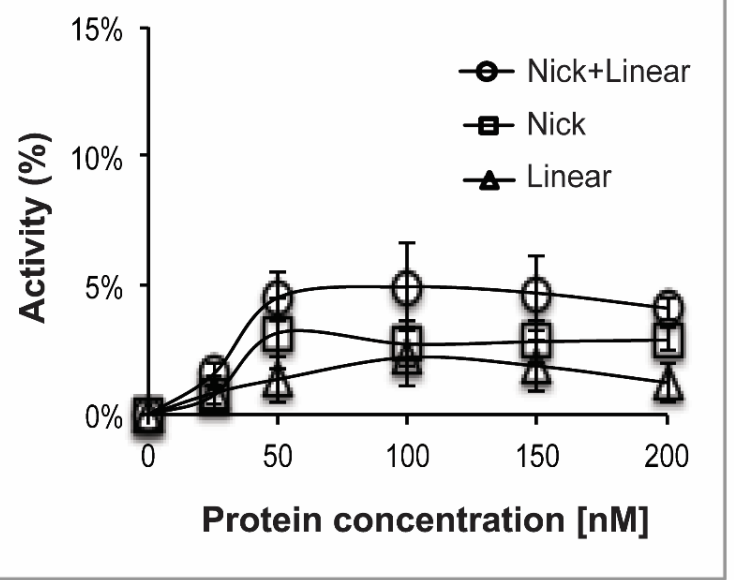

Figure S10. Comparison of cleavage patterns of SpyCas $9^{\mathrm{WT}}$ and $\operatorname{SpyCas} 9^{2 \mathrm{2Pr}}$ proteins on MM5 using $\mathbf{s g R N A}{ }^{\text {del }}$. A) Activity at $10 \mathrm{mM} \mathrm{Mg}^{2+}$ ions on MM5 DNA substrate. B) Activity at $1 \mathrm{mM} \mathrm{Mg}^{2+}$ ions on MM5 DNA substrate. Error bars represent SEM calculated based on three replications. 
Figure S11
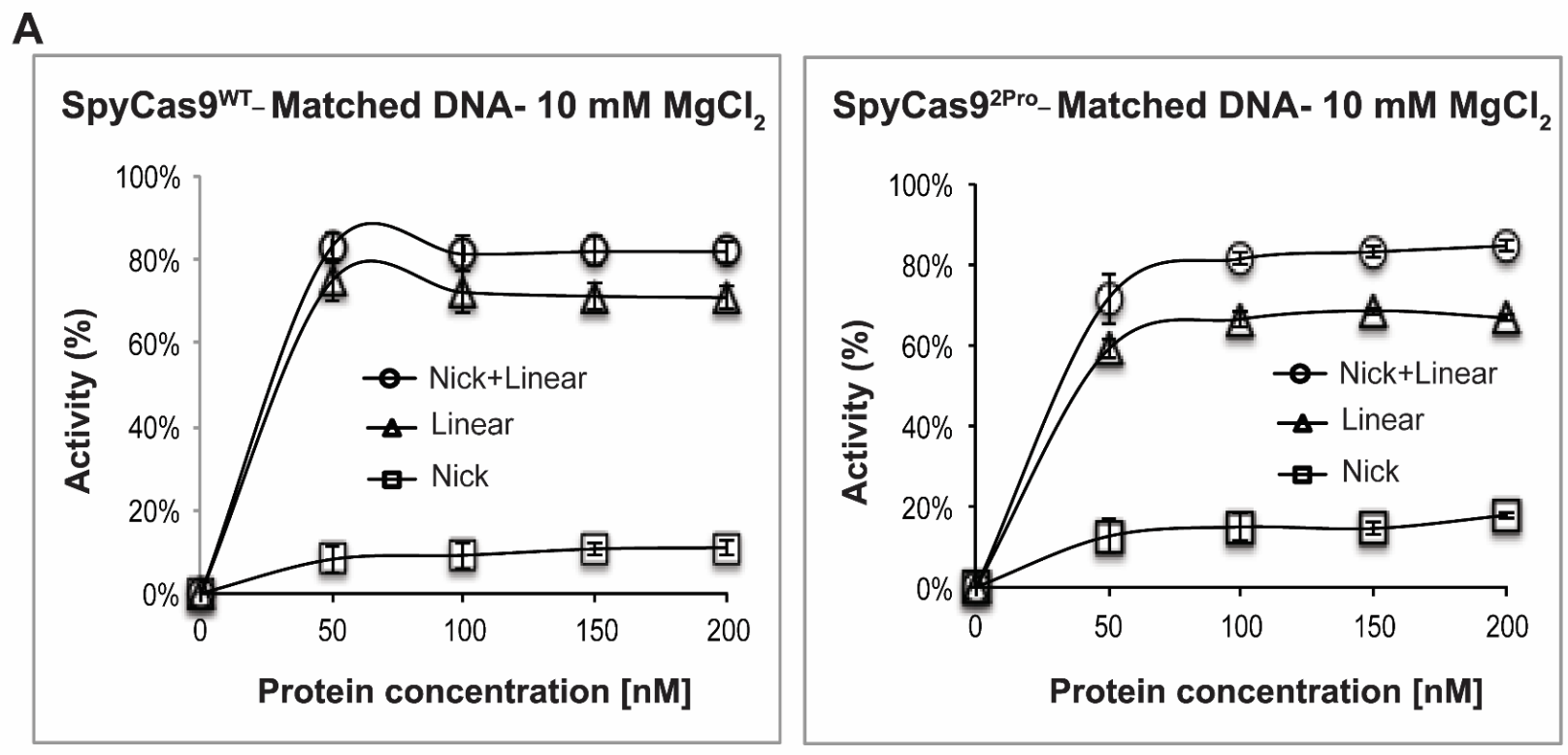

B

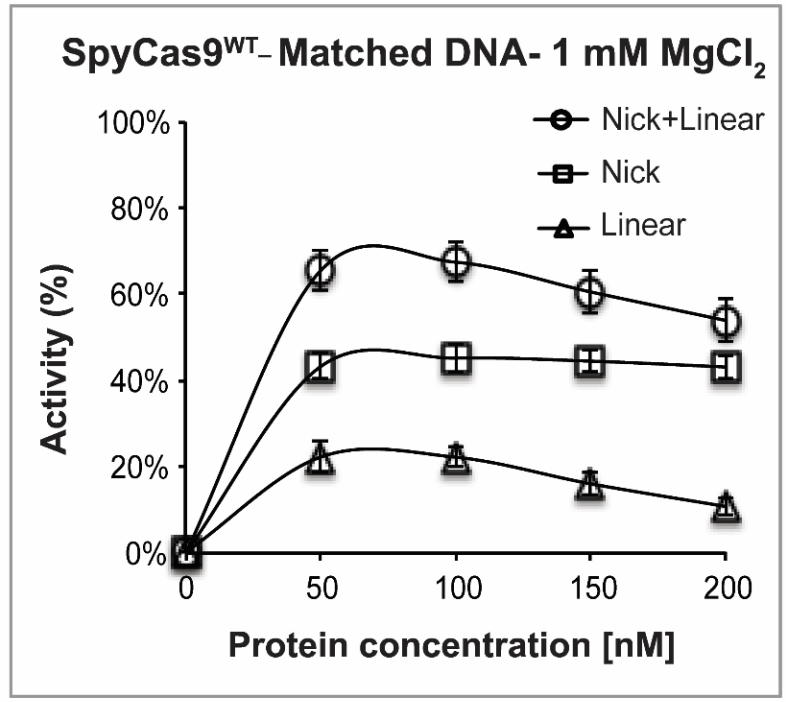

SpyCas92Pro-Matched DNA- 1 mM MgCl

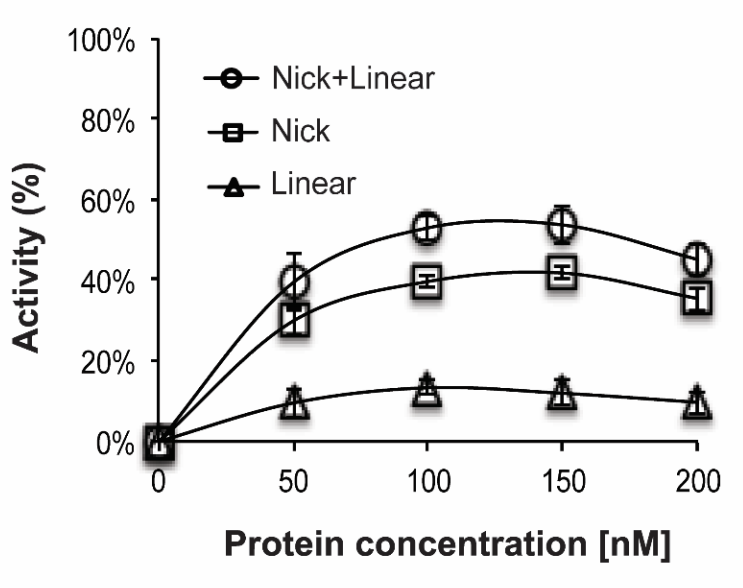

Figure S11. Comparison of cleavage patterns of SpyCas9 ${ }^{\mathrm{WT}}$ and SpyCas9 ${ }^{2 \mathrm{2Pr}}$ proteins on matched DNA using $\operatorname{sgRNA}^{\mathbf{F L}}$. A) Activity at $10 \mathrm{mM} \mathrm{Mg}^{2+}$ ions and a fully matched DNA

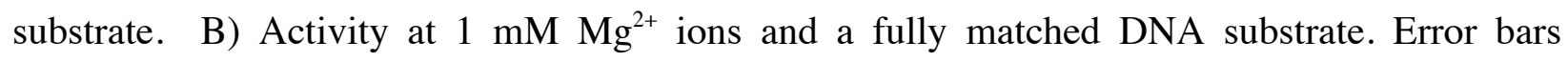
represent SEM calculated based on three replications. 
Figure S12
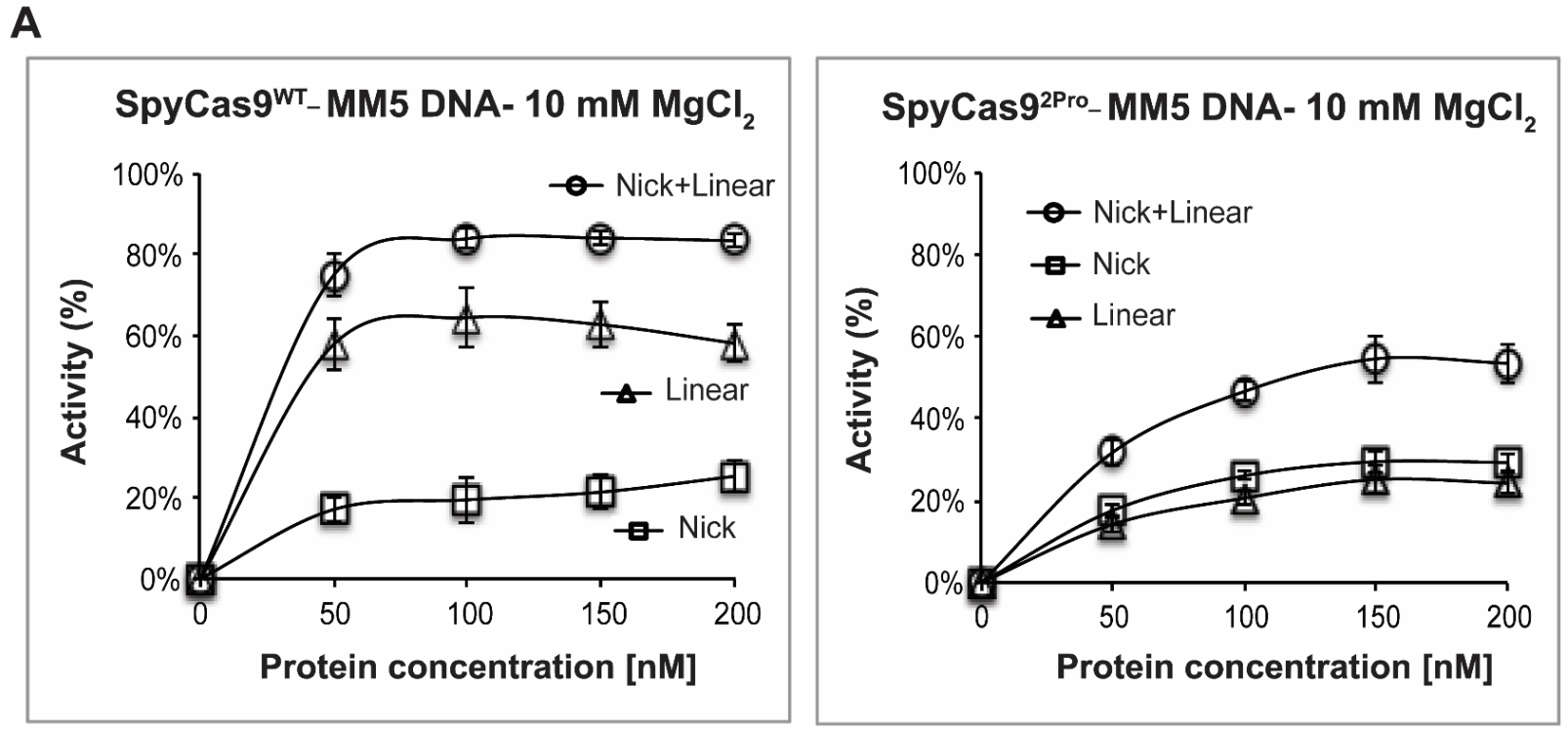

B
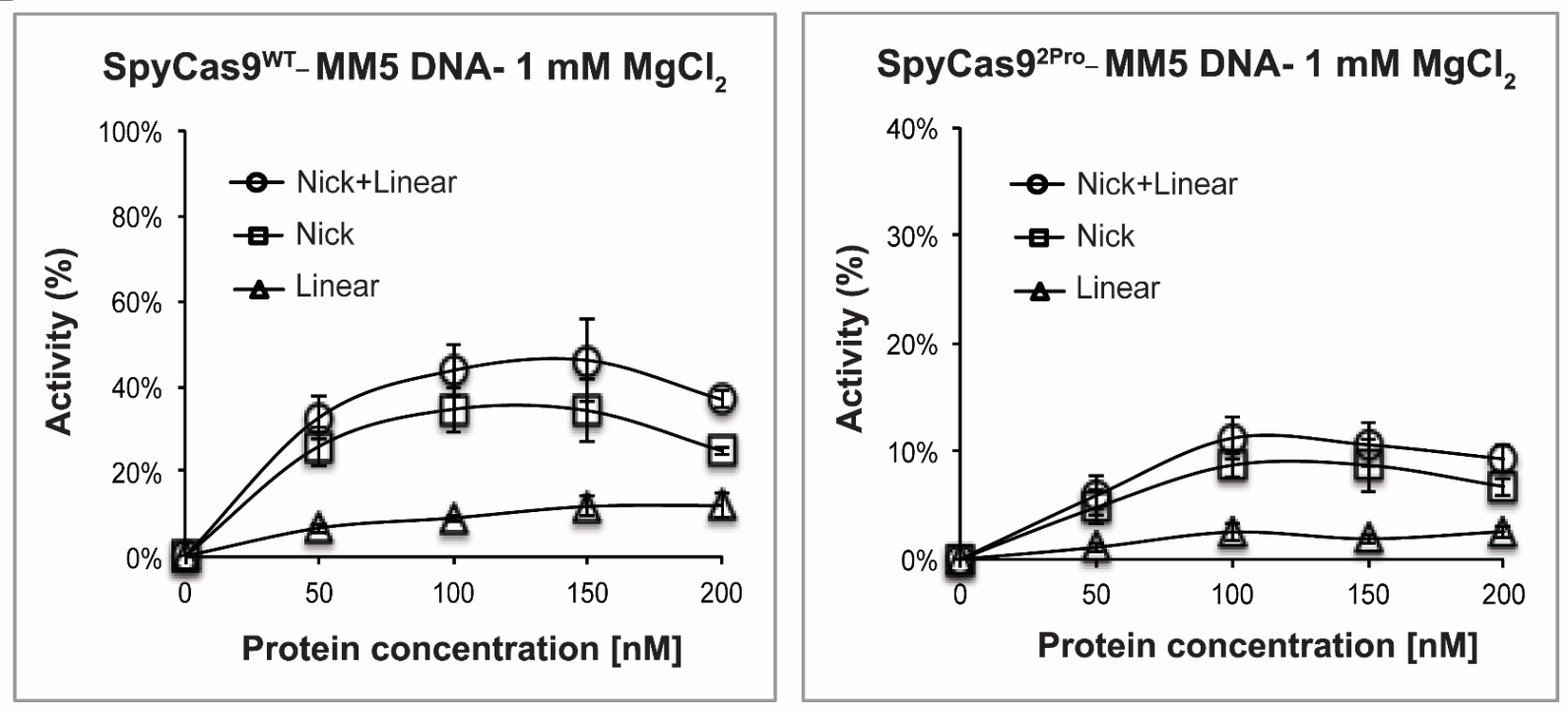

Figure S12. Comparison of cleavage patterns of SpyCas9 ${ }^{\mathrm{WT}}$ and SpyCas9 ${ }^{2 \mathrm{Pro}}$ proteins on MM5 using $\mathbf{s g R N A}{ }^{\mathrm{FL}}$. A) Activity at $10 \mathrm{mM} \mathrm{Mg}^{2+}$ ions on MM5 DNA substrate. B) Activity at $1 \mathrm{mM} \mathrm{Mg}{ }^{2+}$ ions on MM5 DNA substrate. Error bars represent SEM calculated based on three replications. 


\section{Figure S13}

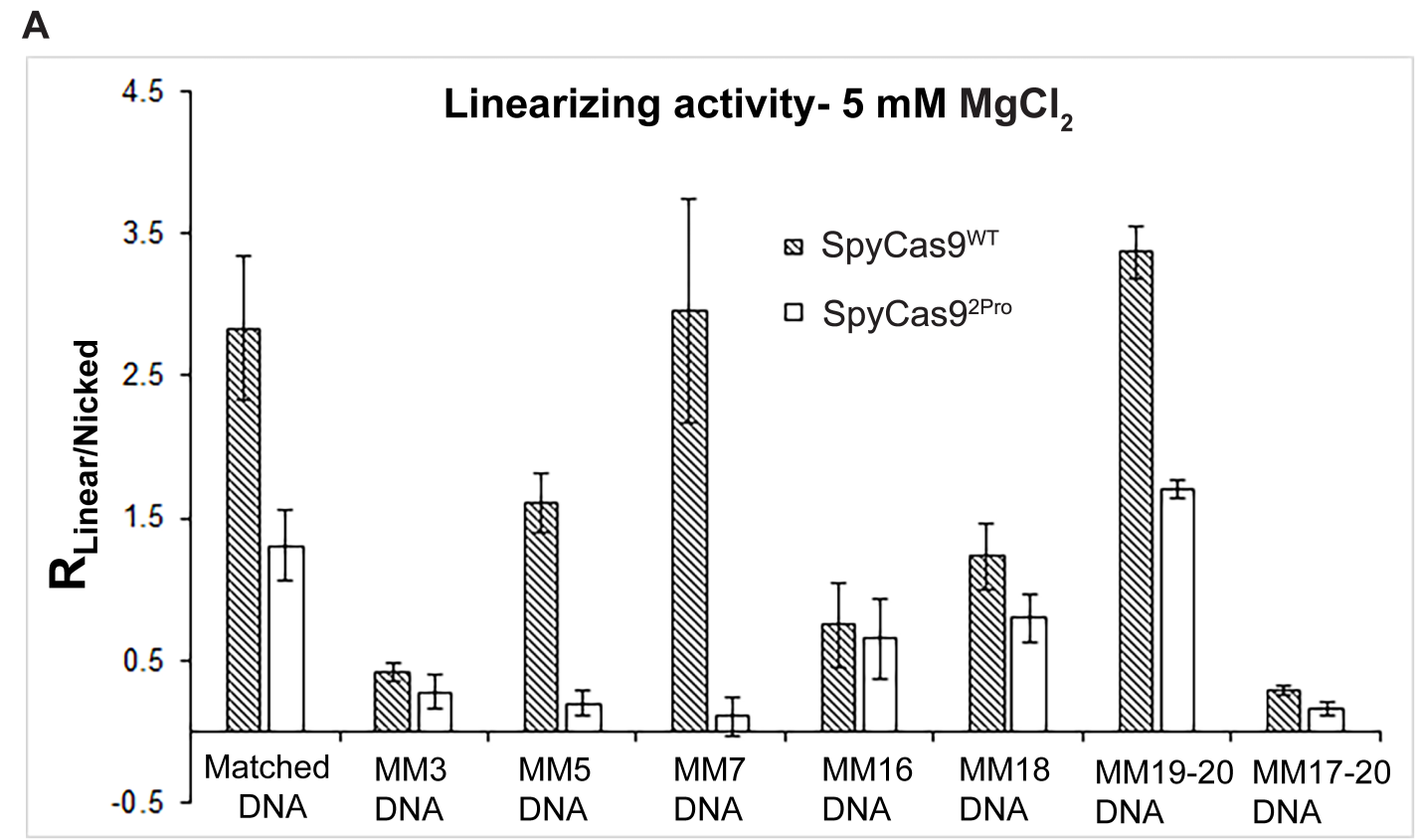

B

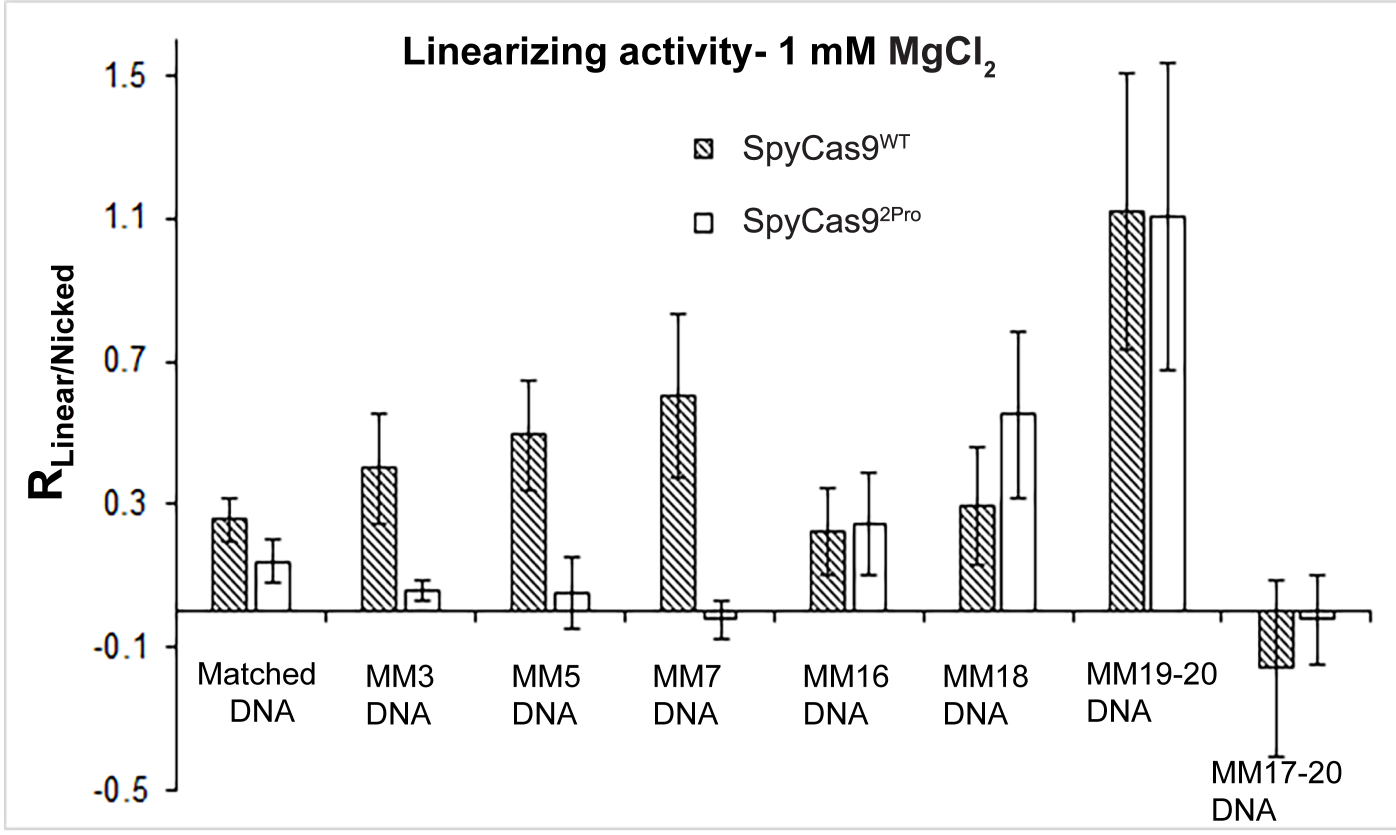

Figure S13. Linearization activity of $\operatorname{SpyCas}^{\mathrm{WT}}$ and $\mathrm{SpyCas}^{2 \mathrm{Pro}}$ on different DNA substrates. A) Reactions performed at $5 \mathrm{mM} \mathrm{MgCl}_{2}$. B) Reactions performed at $1 \mathrm{mM} \mathrm{MgCl}_{2}$. Bar graphs show the ratio of linear over nicked products $\left(\mathrm{R}_{\mathrm{L} / \mathrm{N}}\right.$, see Materials and Methods $)$ from SpyCas9 activity. The ratios were obtained for a protein concentration of $50 \mathrm{nM}$ for the different DNA substrates. For matched DNA and MM5 DNA, there are nine and six different replications respectively, while there are three replications for the rest of the DNA substrates. Error bars represent SEM calculated based on the total number of replications used for each sample. 


\section{Figure S14}
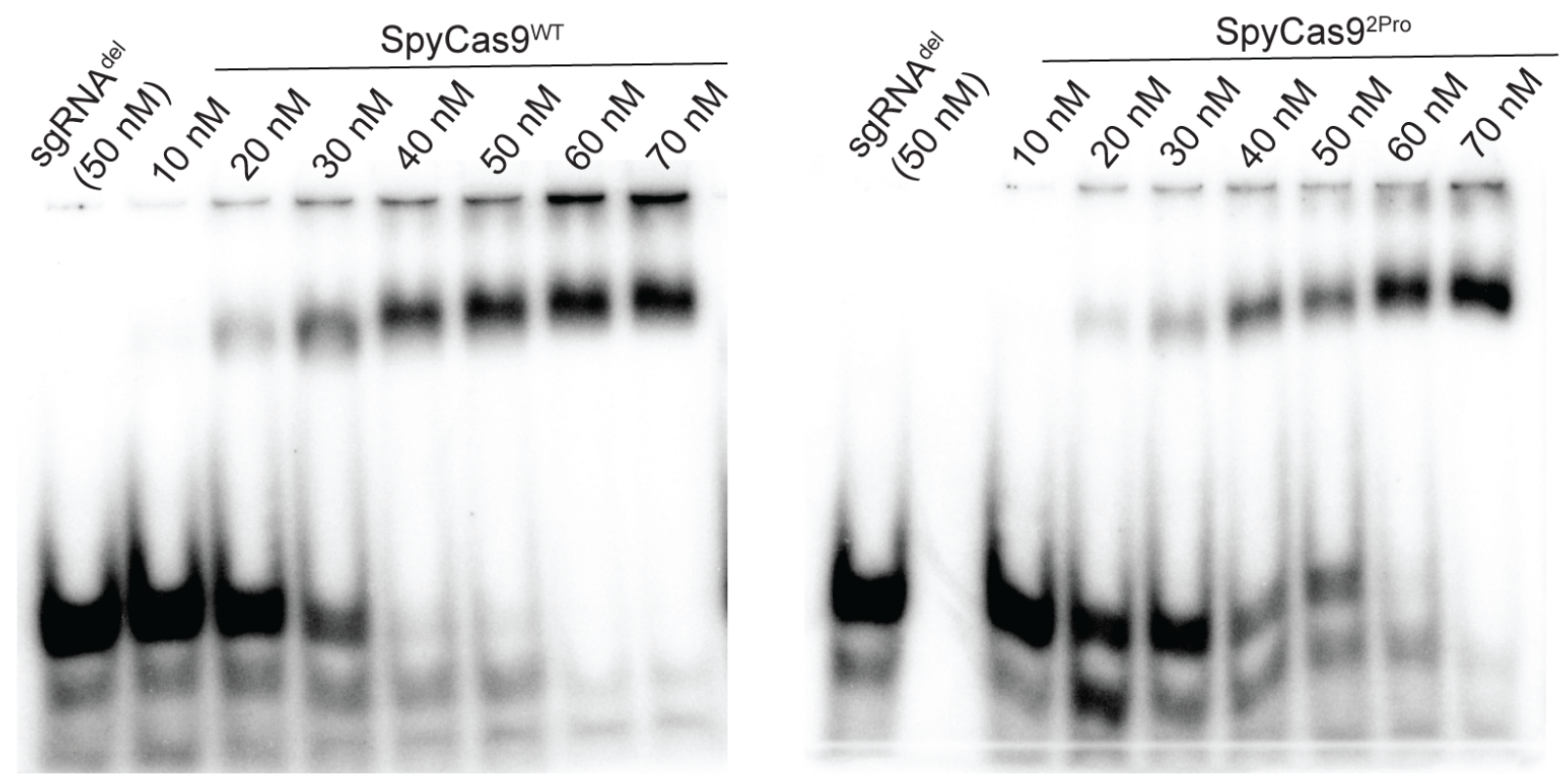

Figure S14. EMSA of SpyCas9 ${ }^{\text {WT }}$ and SpyCas9 $9^{2 \text { Pro }}$ using $5^{\prime}-{ }^{32}$ P-labelled sgRNA ${ }^{\text {del }}$. EMSA was carried out with increasing concentrations of protein $(10 \mathrm{nM}$ to $70 \mathrm{nM})$ at a constant RNA concentration of around $50 \mathrm{nM}$. 
Figure S15

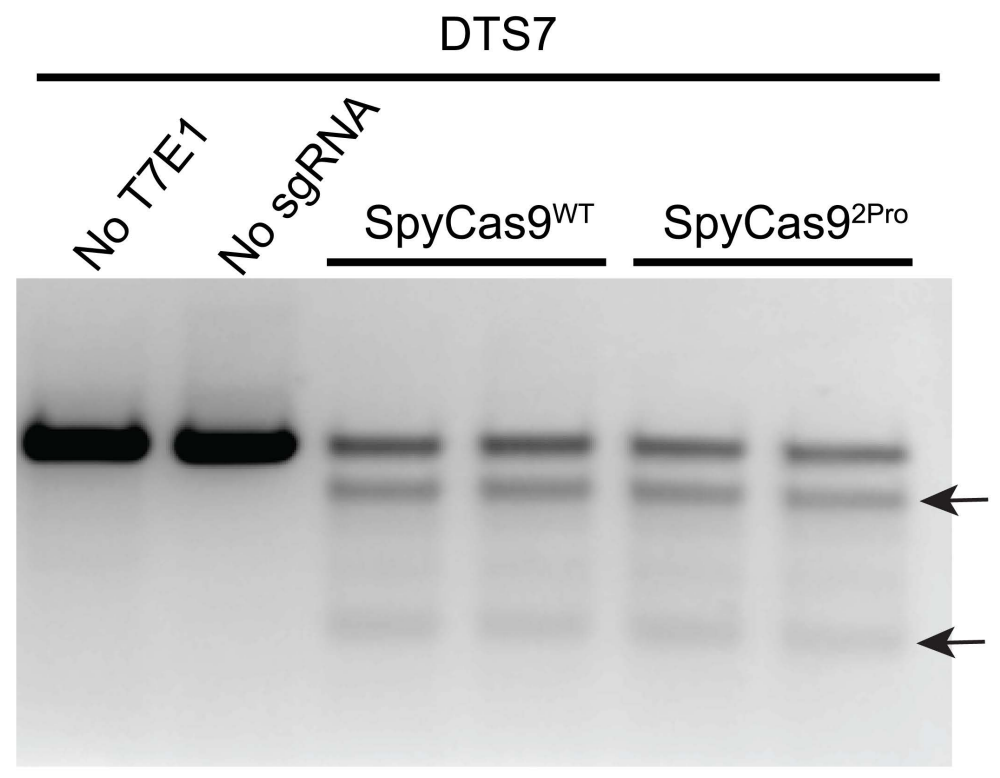

Figure S15. Cleavage activity on HEK293T cells using sgRNA $^{\mathrm{FL}}$. The activity of both SpyCas $9^{\mathrm{WT}}$ and SpyCas9 ${ }^{2 \mathrm{Pro}}$ is similar to that with $\operatorname{sgRNA}{ }^{\text {del }}$. Black arrows indicate cleavage products produced by T7E1 on mismatches created as a result of Cas9 editing. Two replicates are shown for each protein. 


\section{Figure S16}

PAM

On-target 1 GGCACCCTCCATGTACCCAGGGG 23 || ||||||||$\cdot||||||||$. Off-target-1 1 GGTACCСTCCATATACCCAGGGA 23

On-target 1 GGCACССтCСАTGTACCCAGGGG 23 ||$\cdot|||||| \cdot|||||||| \ldots \mid$

Off-target-2 1 GGTACCCTCCCTGTACCCAGAAG 23

On-target 1 GGCACССTCCATGTACCCAGGGG 23 ||$\cdot|||||| \cdot|\cdot||||||| \cdot||$

Off-target-3 1 GGTACCCTCCCTATACCCAGAGG 23

On-target 1 GGCACCCTCCATGTACCCAGGGG 23

||||$\cdot|| \cdot|||\cdot||||||||\cdot| \mid$

Off-target-4 1 GGCAGCCACCAAGTACCCAGAGG 23

On-target 1 GGCACCCTCCATGTACCCAGGGG 23 ||$|\cdot||\cdot||| \cdot|||||||\cdot| \mid$

Off-target-5 1 GGCAGCCACCACGTACCCAGAGG 23

On-target 1 GGCACССTCCATGTACCCAGGGG 23 || ||||||$|\cdot||||||\cdot| \cdot||$

Off-target-6 1 GGTACССTCCCTGTACCCTGAGG 23

On-target 1 GGCACCCTCCATGTACCCAGGGG 23 || ||||||$|\cdot||||||| \ldots||$

Off-target-7 1 GGTACССTCCCTGTACCCAAAGG 23

On-target 1 GGCACССTCCATGTACCCAGGGg 23 || ||||||$|\cdot||||||\cdot| \mid$

Off-target-8 1 GGCTCCСTCCAAGTACCCACTGG 23

Figure S16. Position of the mismatches between the on-target DTS7 sequence and the off-targets. The off-targets tested have up to four mismatches including in the PAM sequence. Needle program from EMBL-EBI (https://www.ebi.ac.uk/Tools/psa/emboss_needle/ nucleotide.html) was used to produce the alignments. 


\section{SUPPLEMENTARY TABLES}

\section{Table S1}

\begin{tabular}{|c|c|c|}
\hline Primers used & Construct & $\begin{array}{c}\text { Method of } \\
\text { mutagenesis }\end{array}$ \\
\hline $\begin{array}{l}\text { FP: 5'-GGAAGCGACTCGTCCTCCACGGACAGCTCGTA-3' } \\
\text { RP: 5'-TACGAGCTGTCCGTGGAGGACGAGTCGCTTCC-3' }\end{array}$ & $\begin{array}{l}\text { SpyCas92Pro } \\
\text { (L64P-K65P) }\end{array}$ & $\begin{array}{l}\text { Site directed } \\
\text { mutagenesis }\end{array}$ \\
\hline $\begin{array}{l}\text { FP: 5'-AAGCCACGCGGCCTCCTAGAACAGCACG-3' } \\
\text { RP: 5'-CGTGCTGTTCTAGGAGGCCGCGTGGCTT-3' }\end{array}$ & $\begin{array}{l}\text { SpyCas9 } 9^{2 \text { Pro }} \text { for } \\
\text { cell-based } \\
\text { assays }\end{array}$ & $\begin{array}{l}\text { Site directed } \\
\text { mutagenesis }\end{array}$ \\
\hline $\begin{array}{l}\text { FP: 5'- } \\
\text { gatccTGCGCTGGTTGATTTCTTCTTGCGCATTTTGGGg-3, } \\
\text { RP: 5'- } \\
\text { aattcCCCAAAATGCGCAAGAAGAAATCAACCAGCGCAg-3, }\end{array}$ & MM5 DNA & Annealing \\
\hline $\begin{array}{l}\text { FP: 5'-GATTTCTTCTTGCGCTTTTTGGGGAATTCAC-3' } \\
\text { RP: 5'-GTGAATTCCCCAAAA } \underline{A} \text { GCGCAAGAAGAAATC-3' }\end{array}$ & $\begin{array}{l}\text { Wild-type } \\
\text { substrate } \\
\text { (Matched DNA) }\end{array}$ & $\begin{array}{l}\text { Site directed } \\
\text { mutagenesis }\end{array}$ \\
\hline $\begin{array}{l}\text { FP: 5'- } \\
\text { CTTGCGCTTATTGGGGAATTCACTGGCCGTCGTTTTACA } \\
\text { A-3' } \\
\text { RP:5'- } \\
\text { ATTCCCCAATAAGCGCAAGAAGAAATCAACCAGCGCAG } \\
\text { GA-3' }\end{array}$ & MM3 DNA & SLIC $^{5}$ \\
\hline $\begin{array}{l}\text { FP: 5'- } \\
\text { TCTTCTTGCECTTTTTGGGGAATTCACTGGCCGTCGTTTT- } \\
\text { 3' } \\
\text { RP: 5'-CCCAAAAAG } \\
\text { ACCAGCAAGAAGAAATCA } \\
\text { ACAGGATCCT-3' }\end{array}$ & MM7 DNA & SLIC $^{5}$ \\
\hline $\begin{array}{l}\text { FP: 5'-TCCTGCGCTGGTTGATTACTTCTTGCGCTTTTTGG- } \\
\text { 3' } \\
\text { RP: 5'-CCAA AAAGCGCAAGAAGTA } \\
\text { ATCAACCAGCGCAGGA-3' }\end{array}$ & MM16 DNA & SPRINP $^{6}$ \\
\hline $\begin{array}{l}\text { FP: 5'- } \\
\text { GGATCCTGCGCTGGTTGA } 1 \text { TTCTTCTTGCGCTTTTTG-3' } \\
\text { RP: 5'-CAAA AAGCGCAAGAAGAATTCA } \\
\text { ACCAGCGCAGGATCC-3' }\end{array}$ & MM18 DNA & SPRINP $^{6}$ \\
\hline $\begin{array}{l}\text { FP: 5'- } \\
\text { GCGCTGGTTCTTTTCTTCTTGCGCTTTTTGGGGAATTCAC } \\
\text { TGG-3' } \\
\text { RP: 5'- } \\
\text { GCAAGAAGAAAAGAACCAGCGCAGGATCCTCTAGAGTC } \\
\text { GACCT-3' }\end{array}$ & MM19-20 DNA & SLIC $^{5}$ \\
\hline $\begin{array}{l}\text { FP: 5'- } \\
\text { GCGCTGGTTCTAATCTTCTTGCGCTTTTTGGGGAATTCAC } \\
\text { TGG-3' } \\
\text { RP: 5'- } \\
\text { GCAAGAAGATTAGAACCAGCGCAGGATCCTCTAGAGTC } \\
\text { GACCT-3' }\end{array}$ & MM17-20 DNA & SLIC $^{5}$ \\
\hline
\end{tabular}


Table S1. List of primers used for creating protein variants and substrate DNA. Bold and underlined sequences represent mutations. Lower case letters in MM5 DNA are restriction sites as they exist after cleavage by the restriction enzyme. 


\section{Table S2}

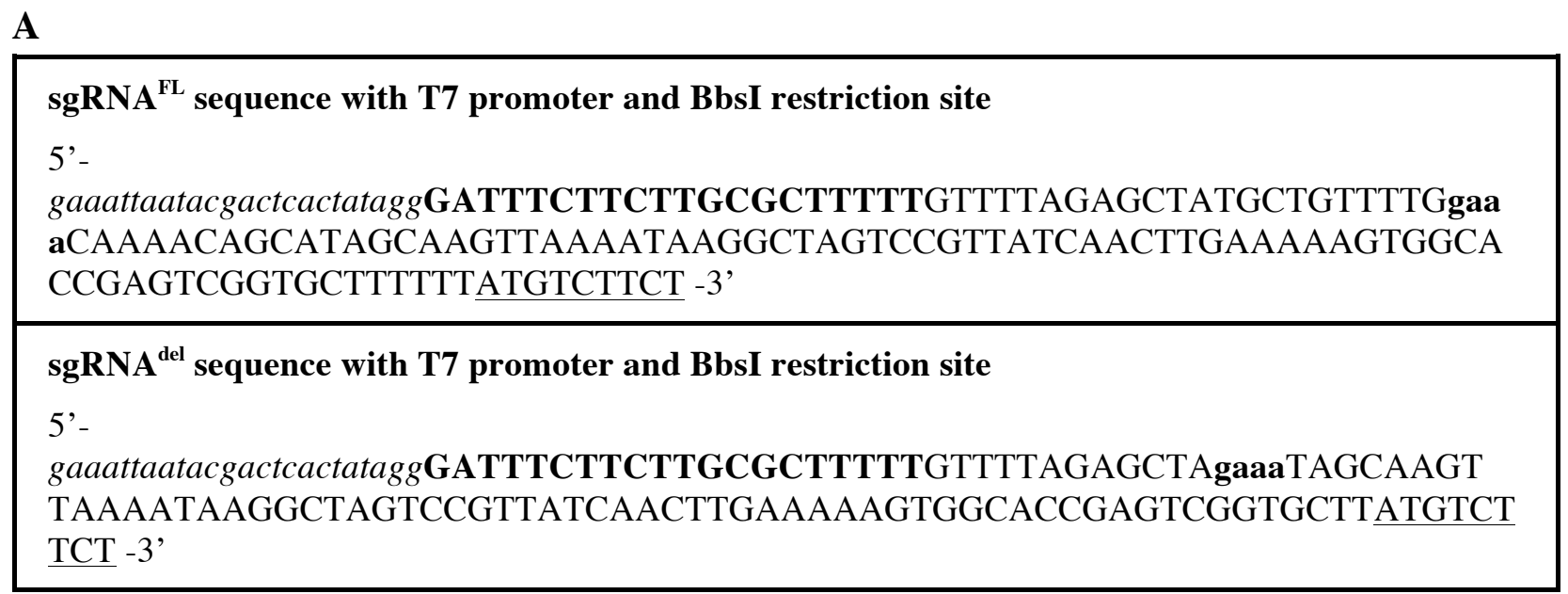

B

sgRNA $^{\text {del }}$ for cell-based assay (Addgene 50920)

5'- CACCGGTGTGCAGGTGAGTGATCAAGAACCTGCTGACGTTTTAGAGCTAGAAATAGC AAGTTAAAATAAGGCTAGTCCGTTATCAACTTGAAAAAGTGGCACCGAGTCGGTGCTTTTTT $\mathrm{T}-3$,

$\operatorname{sgRNA}^{\mathrm{FL}}$ for cell-based assay

(i) Fragment 1: amplifies 1 to 4057 of pLK.O1

Forward primer: 5'- GAATTCTCGACCTCGAGACAAATGGCAGTATTCATCCACA -3'

Reverse primer: 5'- CTACGGCTACACTAGAAGAACAGTATTTGGTATCTGCGC -3'

(ii) Fragment 2: amplifies 4017 to 8112 of pLK.O1

Forward primer: 5'- GCGCAGATACCAAATACTGTTCTTCTAGTGTAGCCGTAG -3'

Reverse primer: 5'- GTCAGCAGGTTCTTGATCCGTCGGAATTGCCAG -3'

(iii) $\mathrm{sgRNA}^{\mathrm{FL}}$ sequence: ordered as gBlock from IDT

5'-

ctggcaattccgacggatcaagaacetgctgacGTTTTAGAGCTATGCTGTTTTGGAAACAAAACAGCATAGCA AGTTAAAATAAGGCTAGTCCGTTATCAACTTGAAAAAGTGGCACCGAGTCGGTGCTTTTTTga attctcgacctcgagacaaatggcagtattcatccaca -3 '

sgRNA Forward primer: 5'- CTGGCAATTCCGACGGATCAAGAACCTGCTGAC -3'

sgRNA Reverse primer: 5' - TGTGGATGAATACTGCCATTTGTCTCGAGGTCGAGAATTC -3'

The fragments i, ii were mixed with sgRNA sequence (iii) in 1:1:3 ratio and subjected to Gibson cloning (New England Biolabs-E5510S).

Table S2. sgRNA constructs used for in vitro and cell-based studies. A) Sequence of $\operatorname{sgRNA}^{\mathrm{FL}}$ and sgRNA $^{\text {del }}$ along with the $\mathrm{T} 7$ promoter sequence used to facilitate in vitro transcription. T7 promoter is in italics, bold-upper case sequence is guide region, and tetra loop is in bold-lower case. BbsI (underlined sequence) is used to linearize the template before transcription. B) sgRNA sequence used for the cell-based assays. Nucleotides in bold are the recognition sites for type IIS BfuAI enzyme that is used to insert different guide sequences (Table S3) at the underlined region. Nucleotides after the underlined sequence are the sgRNA ${ }^{\text {del }}$ 
backbone used in the cell-based assays. This sgRNA version is identical to that used in the in vitro assays except for the presence of five additional nucleotides (Ts) at the 3'-end. The nucleotide with gray shade represents U6 promoter transcription start site. $\operatorname{sgRNA}{ }^{\mathrm{FL}}$ was created by Gibson assembly? 


\section{Table S3}

\begin{tabular}{|c|c|c|c|}
\hline Site & Gene & Guide region of sgRNA & Target site \\
\hline STS1 & VEGF & \begin{tabular}{|l|}
$5^{\prime}-$ \\
GGGUGGGGGGAGUUUGCUC \\
C-3'
\end{tabular} & $\begin{array}{l}\text { 5'- } \\
\text { AGGGGGTGGGGGGAGTTTGCTCCTGG } \\
\text { ACC-3, }\end{array}$ \\
\hline STS3 & VEGF & \begin{tabular}{|l|}
$5^{\prime}-$ \\
GGUGAGUGAGUGUGUGCGU \\
G-3'
\end{tabular} & \begin{tabular}{|l|}
$5^{\prime}-$ \\
GTGGGTGAGTGAGTGTGTGCGTGTGGG \\
GT-3,
\end{tabular} \\
\hline DTS4 & PAX2 & $\begin{array}{l}\text { 5'- } \\
\text { GAACCCGACUAUGUUCGCC } \\
\text { U-3' }\end{array}$ & $\begin{array}{l}5^{\prime}- \\
\text { ACAGAACCCGACTATGTTCGCCTGGGA } \\
\text { GA-3, }\end{array}$ \\
\hline DTS7 & LSP1 & \begin{tabular}{|l|}
$5 '-$ \\
GGCACCCUCCAUGUACCCAG \\
-3,
\end{tabular} & \begin{tabular}{|l|} 
5'- \\
GCTGGCACCCTCCATGTACCCAGGGGA \\
GA-3,
\end{tabular} \\
\hline DTS8 & PCDHB4 & \begin{tabular}{|l|} 
5'- \\
GUGAAGAUAUGAUAAGUUC \\
U-3'
\end{tabular} & \begin{tabular}{|l}
$5^{\prime}-$ \\
TGAGTGAAGATATGATAAGTTCTGGGA \\
GA-3' \\
\end{tabular} \\
\hline DTS10 & PRKD3 & \begin{tabular}{|l|} 
5'- \\
GAAAAUGAGGACAUUUGAG \\
A-3, \\
\end{tabular} & $\begin{array}{l}\text { '- } \\
\text { AATGAAAATGAGGACATTTGAGAAGG } \\
\text { TGA-3' } \\
\end{array}$ \\
\hline DTS55 & CYBB & \begin{tabular}{|l|}
5 \\
GAUUACUGUGUGGUAGAGG \\
G-3'
\end{tabular} & \begin{tabular}{|l} 
5'- \\
CTGGATTACTGTGTGGTAGAGGGAGGT \\
GA-3'
\end{tabular} \\
\hline
\end{tabular}

Table S3. List of sites tested by cell-based assays. Sequences for the guide region of sgRNA and the target DNA are shown for each site. PAM regions are underlined. 


\section{Table S4}

\begin{tabular}{|c|c|c|c|c|}
\hline $\begin{array}{l}\text { Plasmid } \\
\text { name/construct }\end{array}$ & Source & $\begin{array}{l}\text { Target } \\
\text { site }\end{array}$ & $\begin{array}{l}\text { Forward-oligo spacer } \\
\text { cloning }\end{array}$ & $\begin{array}{l}\text { Reverse-oligo spacer } \\
\text { cloning }\end{array}$ \\
\hline SpyCas9 ${ }^{\mathrm{WT}}$ & $\begin{array}{l}\text { Addgene } \\
\text { (PMJ806) }\end{array}$ & NA & NA & NA \\
\hline SpyCas $9^{2 \text { Pro }}$ & This study & NA & NA & NA \\
\hline $\begin{array}{l}\text { pCSDest2-SpyCas9- } \\
\text { NLS-3XHA-NLS }\end{array}$ & $\begin{array}{l}\text { Addgene } \\
69220\end{array}$ & NA & NA & NA \\
\hline $\begin{array}{l}\text { pCSDest2- } \\
\text { SpyCas9 }{ }^{2 \text { Pro }} \text {-NLS- } \\
\text { 3XHA-NLS }\end{array}$ & This study & NA & NA & NA \\
\hline $\begin{array}{l}\text { pLK.O1-puro U6 } \\
\text { sgRNA }\end{array}$ & $\begin{array}{l}\text { Addgene } \\
50920\end{array}$ & empty & NA & NA \\
\hline $\begin{array}{l}\text { pEJS839: pLK.O1 } \\
\text { Spy SgRNA }\end{array}$ & 8 & STS1 & NA & NA \\
\hline $\begin{array}{l}\text { pEJS505: pLK.O1 } \\
\text { SpySgRNA }\end{array}$ & 8 & STS3 & NA & NA \\
\hline $\begin{array}{l}\text { pEJS864: pLK.O1 } \\
\text { SpySgRNA }\end{array}$ & This study & DTS4 & \begin{tabular}{|l|}
$5^{\prime}-$ \\
ACCGGAACCCGACTAT \\
GTTCGCCT-3' \\
\end{tabular} & $\begin{array}{l}\text { 5'- } \\
\text { AAACAGGCGAACATAGT } \\
\text { CGGGTTC-3' }\end{array}$ \\
\hline $\begin{array}{l}\text { pEJS400: pLK.O1 } \\
\text { SpySgRNA }\end{array}$ & 9 & DTS7 & $\begin{array}{l}5^{\prime}- \\
\text { ACCGGCACCCTCCATG } \\
\text { TACCCAG-3' }\end{array}$ & $\begin{array}{l}\text { 5'- } \\
\text { AAACCTGGGTACATGGA } \\
\text { GGGTGCC-3' }\end{array}$ \\
\hline $\begin{array}{l}\text { pEJS349: pLK.O1 } \\
\text { puro-Spy SgRNA- } \\
\text { DTS7/21nt-extra G }\end{array}$ & 9 & DTS7 & $\begin{array}{l}5^{\prime}- \\
\text { ACCGGGCACCCTCCAT } \\
\text { GTACCCAG-3' }\end{array}$ & $\begin{array}{l}\text { 5'- } \\
\text { AAACCTGGGTACATGGA } \\
\text { GGGTGCC-3' }\end{array}$ \\
\hline $\begin{array}{l}\text { pEJS784: pLK.O1 } \\
\text { Full length DTS7 } \\
\text { guide-Spy 20nt } \\
\end{array}$ & This study & DTS7 & $\begin{array}{l}5^{\prime}- \\
\text { ACCGGCACCCTCCATG } \\
\text { TACCCAG-3' } \\
\end{array}$ & $\begin{array}{l}\text { '- } \\
\text { AAACCTGGGTACATGGA } \\
\text { GGGTGCC-3' } \\
\end{array}$ \\
\hline $\begin{array}{l}\text { pEJS752: pLK.O1 } \\
\text { Full length DTS7 } \\
\text { guide-Spy 21nt-extra } \\
\text { G }\end{array}$ & This study & DTS7 & $\begin{array}{l}5^{\prime}- \\
\text { ACCGGGCACCCTCCAT } \\
\text { GTACCCAG-3' }\end{array}$ & $\begin{array}{l}\text { 5'- } \\
\text { AAACCTGGGTACATGGA } \\
\text { GGGTGCC-3' }\end{array}$ \\
\hline $\begin{array}{l}\text { pEJS401: pLK.O1 } \\
\text { SpySgRNA }\end{array}$ & 9 & DTS8 & $\begin{array}{l}\text { '- } \\
\text { ACCGGTGAAGATATGA } \\
\text { TAAGTTCT-3' }\end{array}$ & $\begin{array}{l}\text { '- } \\
\text { AAACAGAACTTATCATA } \\
\text { TCTTCAC-3' }\end{array}$ \\
\hline $\begin{array}{l}\text { pEJS548: pLK.O1 } \\
\text { SpySgRNA }\end{array}$ & This study & DTS10 & $\begin{array}{l}\text { '- } \\
\text { ACCGAAAATGAGGACA } \\
\text { TTTGAGA-3' }\end{array}$ & $\begin{array}{l}\text { '- } \\
\text { AAACTCTCAAATGTCCT } \\
\text { CATTTTC-3' }\end{array}$ \\
\hline $\begin{array}{l}\text { pEJS865: pLK.O1- } \\
\text { SpySgRNA }\end{array}$ & 9 & DTS55 & $\begin{array}{l}\text { '’- } \\
\text { ACCGCTGGATTACTGT } \\
\text { GTGGTAGAGGG-3' }\end{array}$ & $\begin{array}{l}\text { '- } \\
\text { CAACCCCTCTACCACAC } \\
\text { AGTAATCCAG-3' }\end{array}$ \\
\hline
\end{tabular}

Table S4: List of plasmids used in cell-based study. 
Table S5

\begin{tabular}{|c|l|l|}
\hline Site & \multicolumn{1}{|c|}{ Oligo-forward } & \multicolumn{1}{c|}{ Oligo-reverse } \\
\hline STS1 & $\begin{array}{l}\text { 5'- } \\
\text { ACACACACGTCCTCACTCTCGAAGAC- } \\
\text { 3' }\end{array}$ & $\begin{array}{l}\text { 5'- } \\
\text { TCTCTGTACATGAAGCAACTCCAGTCC- } \\
\text { 3' }\end{array}$ \\
\hline STS3 & $\begin{array}{l}\text { 5'-GTGTGCAGACGGCAGTCACTAGG- } \\
\text { 3' }\end{array}$ & $\begin{array}{l}\text { 5'- } \\
\text { CGTTCCCTCTTTGCTAGGAATATTGAAG- } \\
\text { 3' }\end{array}$ \\
\hline DTS4 & 5'-CACCCTCAGGAAGTCAGCTC-3' & 5'-TGCTCACCTGTTGATGGAAG-3' \\
\hline DTS7 & 5'-AGGACTGCTCTCAGCTACCG-3' & 5'-AAGGGCAGAGAGGCTAAAGG-3' \\
\hline DTS8 & 5'-CAATGCTCCTGAGTTTGTGC-3' & 5'-CGGTCCAGTGGTCTCTCTGT-3' \\
\hline DTS10 & 5'-GCATCAGCTTTTCTCGATGG-3' & 5'-AGGAAGACAACCAGGGATTTG-3' \\
\hline DTS55 & $\begin{array}{l}\text { 5'-AAAGATCACTATGGAGCTGAAGG- } \\
\text { 3' }\end{array}$ & 5'-AACCTCTCCACCCTGTGTTG-3' \\
\hline
\end{tabular}

Table S5. List of oligos used for TIDE and T7E1 analyses. Primer sequences used to amplify different target sites. 
Table S6

\begin{tabular}{|c|c|c|c|}
\hline Nam & 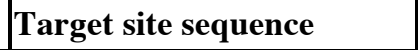 & & $r$ \\
\hline & $\begin{array}{l}5^{\prime}- \\
\text { GGCACCCTCCATGTAC } \\
\text { CCAGGGG-3' }\end{array}$ & $\begin{array}{l}5 '- \\
\text { ctacacgacgctcttccgatctGCACCCCAT } \\
\text { GCCTATGTT-3, }\end{array}$ & $\begin{array}{l}\text { agacgtgtgctcttccgatctCTATTCA } \\
\text { TTTAGATTTTTTTTCTCTG } \\
\text { TCC-3 }\end{array}$ \\
\hline $\mathrm{SpD}$ & CCATATACC & $\begin{array}{l}5 '- \\
\text { ctacacgacgctcttccgat } \\
\text { GAAAGAAAGAA }\end{array}$ & \begin{tabular}{|l}
$5^{\prime}-$ \\
agacgtgtgctcttccgatct \\
TTGTTCAGATTCT
\end{tabular} \\
\hline SpDTS7-OT2 & $\mid \begin{array}{l}5 ’- \\
\text { GGTACCCTCCCTGTACC } \\
\text { CAGAAG-3' }\end{array}$ & $\begin{array}{l}5 '- \\
\text { ctacacgacgctcttccgatctCTGAAATAG } \\
\text { ATTATAAGACCCTCATTC-3' }\end{array}$ & $\begin{array}{l}{ }^{\prime}- \\
\text { agacgtgtgctcttccgatctCTATTCA } \\
\text { TTTAGATTTTTTTTTCTCTG } \\
\text { TCC-3' } \\
\end{array}$ \\
\hline SpDT & \begin{tabular}{|l|} 
'- \\
GGTACCCTCCCTATACC \\
CAGAGG-3' \\
\end{tabular} & $\begin{array}{l}5 '- \\
\text { ctacacgacgctcttccgatctGCAGGTCAT } \\
\text { AGGACCCTC-3' }\end{array}$ & AGAC \\
\hline SpDT & \begin{tabular}{|l|} 
'- \\
GGCAGCCACCAAGTAC \\
CCAGAGG-3' \\
\end{tabular} & $\begin{array}{l}5 \text { '- } \\
\text { ctacacgacgctcttccgatctCATGCACAA } \\
\text { GTGCTAAGAGAC-3, }\end{array}$ & $\begin{array}{l}5^{\prime}- \\
\text { agacgtgtgctcttccgatctTCCAGG } \\
\text { CAGGGAACTCAG-3' }\end{array}$ \\
\hline SpDT & \begin{tabular}{|l|} 
'- \\
GGCAGCCACCACGTAC \\
CCAGAGG-3' \\
\end{tabular} & $\begin{array}{l}\text { 5'- } \\
\text { ctacacgacgctcttccgatctTGGCATGCA } \\
\text { CGAGCACCA-3' }\end{array}$ & $\begin{array}{l}\text { 5'- } \\
\text { agacgtgtgctcttccgatctTGAGGC } \\
\text { CTAGGAGGTTTC-3' }\end{array}$ \\
\hline SpDTs & \begin{tabular}{|l|}
$5^{\prime}-$ \\
GGT \\
CTG $A$ \\
\end{tabular} & $\begin{array}{l}5 '- \\
\text { ctaca } \\
\text { CTG }\end{array}$ & $\begin{array}{l}\text { agacgtgtgctcttccga } \\
\text { ATCCTTCTTAG? }\end{array}$ \\
\hline SpDTS7-OT7 & CCCTGTACC & $\begin{array}{l}5 '- \\
\text { ctacacgacgctcttccgatctGGAGGATAT } \\
\text { TATAAGACCCTCATATG-3' }\end{array}$ & $\begin{array}{l}5^{\prime}- \\
\text { agacgtgtgctcttccgatctTGTTTTG } \\
\text { ATTATTCTCTATGTCCCTA- } \\
\text { 3' }\end{array}$ \\
\hline SpDTS7-OT8 & $\begin{array}{l}\text { 5'- } \\
\text { GGCTCCCTCCAAGTAC } \\
\text { CCACTGG-3' }\end{array}$ & $\begin{array}{l}\text { ctacacgacgetcttccgatctGCCCGATCC } \\
\text { AATCAGCTGTA-3' }\end{array}$ & $\begin{array}{l}5^{\prime} \text { - } \\
\text { agacgtgtgctcttccgatctACTCAG } \\
\text { GGCTCAGGTTGAA-3' }\end{array}$ \\
\hline
\end{tabular}

Table S6. List of off-target sites analyzed and the primers used for targeted-deep sequencing. Primers to amplify regions flanking the off-target (OT) sites (PCR-1). 
Table S7

\begin{tabular}{|c|c|c|c|c|}
\hline Index \# & Sample Name & $\begin{array}{l}\text { Index } \\
\text { Sequence }\end{array}$ & Name & Sequence \\
\hline & & & 5p-univ-sht: & $\begin{array}{l}\text { '- } \\
\text { AATGATACGGCGACCACCGAGATCTAC } \\
\text { ACTCTTTCCCTACACGACGCTCTTCCG- } \\
\text { 3, }\end{array}$ \\
\hline 1 & WT-DTS7-Rep1 & ATCACG & 3p-Adap-Index-1: & $\begin{array}{l}\text { '- } \\
\text { CAAGCAGAAGACGGCATACGAGATCG } \\
\text { TGATGTGACTGGAGTTCAGACGTGTGC } \\
\text { TCTTCCG-3' }\end{array}$ \\
\hline 2 & WT-DTS7-Rep2 & CGATGT & 3p-Adap-Index-2: & $\begin{array}{l}\text { '- } \\
\text { CAAGCAGAAGACGGCATACGAGATAC } \\
\text { ATCGGTGACTGGAGTTCAGACGTGTGC } \\
\text { TCTTCCG-3' }\end{array}$ \\
\hline 3 & WT-DTS7-Rep3 & TTAGGC & 3p-Adap-Index-3: & $\begin{array}{l}\text { '- } \\
\text { CAAGCAGAAGACGGCATACGAGATGC } \\
\text { CTAAGTGACTGGAGTTCAGACGTGTGC } \\
\text { TCTTCCG-3' }\end{array}$ \\
\hline 4 & $\begin{array}{l}\text { 2Pmutant-DTS7- } \\
\text { Rep1 }\end{array}$ & TGACCA & 3p-Adap-Index-4: & $\begin{array}{l}\text { '- } \\
\text { CAAGCAGAAGACGGCATACGAGATTG } \\
\text { GTCAGTGACTGGAGTTCAGACGTGTGC } \\
\text { TCTTCCG-3' }\end{array}$ \\
\hline 5 & $\begin{array}{l}\text { 2Pmutant-DTS7- } \\
\text { Rep2 }\end{array}$ & ACAGTG & 3p-Adap-Index-5: & $\begin{array}{l}\text { 5'- } \\
\text { CAAGCAGAAGACGGCATACGAGATCA } \\
\text { CTGTGTGACTGGAGTTCAGACGTGTGC } \\
\text { TCTTCCG-3' }\end{array}$ \\
\hline 6 & $\begin{array}{l}\text { 2Pmutant-DTS7- } \\
\text { Rep3 }\end{array}$ & GCCAAT & 3p-Adap-Index-6: & $\begin{array}{l}\text { '- } \\
\text { CAAGCAGAAGACGGCATACGAGATAT } \\
\text { TGGCGTGACTGGAGTTCAGACGTGTGC } \\
\text { TCTTCCG-3' }\end{array}$ \\
\hline 7 & $\begin{array}{l}\text { NegCT-DTS7- } \\
\text { Rep1 }\end{array}$ & CAGATC & 3p-Adap-Index-7: & $\begin{array}{l}\text { '- } \\
\text { CAAGCAGAAGACGGCATACGAGATGA } \\
\text { TCTGGTGACTGGAGTTCAGACGTGTGC } \\
\text { TCTTCCG-3' }\end{array}$ \\
\hline 8 & $\begin{array}{l}\text { NegCT-DTS7- } \\
\text { Rep2 }\end{array}$ & ACTTGA & 3p-Adap-Index-8: & $\begin{array}{l}\text { '- } \\
\text { CAAGCAGAAGACGGCATACGAGATTC } \\
\text { AAGTGTGACTGGAGTTCAGACGTGTGC } \\
\text { TCTTCCG-3' }\end{array}$ \\
\hline 9 & $\begin{array}{l}\text { NegCT-DTS7- } \\
\text { Rep3 }\end{array}$ & GATCAG & 3p-Adap-Index-9: & $\begin{array}{l}\text { 5'- } \\
\text { CAAGCAGAAGACGGCATACGAGATCT } \\
\text { GATCGTGACTGGAGTTCAGACGTGTGC } \\
\text { TCTTCCG-3' }\end{array}$ \\
\hline
\end{tabular}

Table S7. List of primers used for targeted-deep sequencing. Primers to add TruSeq adaptor sequences (PCR-2). 
Table S8

A

\begin{tabular}{|l|l|l|l|l|l|l|}
\hline \multirow{2}{*}{ Site } & \multicolumn{3}{|c|}{ SpyCas9 $^{\text {WT }}$} & \multicolumn{3}{c|}{ SpyCas92Pro $^{2}$} \\
& R1 & R2 & R3 & R1 & R2 & R3 \\
\hline STS1 & 22 & 20 & 19.4 & 1 & 0 & 2.1 \\
STS3 & 65.8 & ND & ND & 1.1 & ND & ND \\
DTS4 & 76 & 78 & 74 & 1 & 1 & 3.3 \\
DTS7 & 77 & 57 & 70 & 38 & 50 & 37 \\
DTS8 & 0 & 0 & 2.2 & 2 & 3 & 4.9 \\
DTS10 & 55 & 53 & 52.6 & 0 & 1 & 2.7 \\
DTS55 & 65 & 64 & 66.6 & 18 & 16 & 19.8 \\
\hline
\end{tabular}

B

\begin{tabular}{|l|l|l|l|l|l|l|}
\hline \multirow{2}{*}{ Site } & \multicolumn{3}{|c|}{ SpyCas9 } & \multicolumn{3}{c|}{ SpyCas9 $^{\text {2Pro }}$} \\
\hline & R1 & R2 & R3 & R1 & R2 & R3 \\
\hline On-target & 62.93 & 64.45 & 64.56 & 35.37 & 38.4 & 41.67 \\
OT1 & 18.79 & 22.08 & 20.56 & 2.05 & 3.63 & 2.89 \\
OT2 & 1.71 & 1.62 & 1.22 & 0.07 & 0.29 & 0.20 \\
OT3 & 12.74 & 12.5 & 11.68 & 0.42 & 1.76 & 0.89 \\
OT4 & 4.25 & 3.79 & 4.58 & 0.03 & 0.09 & 0.04 \\
OT5 & 3.75 & 4.05 & 3.44 & 0.03 & 0.05 & 0.06 \\
OT6 & 8.98 & 8.48 & 8.8 & 0.18 & 0.62 & 0.55 \\
OT7 & 3.07 & 2.93 & 2.83 & 0.06 & 0.2 & 0.33 \\
OT8 & 3.67 & 3.86 & 3.43 & 0.08 & 0.22 & 0.47 \\
\hline
\end{tabular}


Table S8. Indel calculation for cell-based assays. A) Percentage (\%) of indels based on the TIDE assay for different target sites. B) Percentage (\%) of indels as observed by the targeted deep-sequencing analysis. Three replicates are shown (R1-R3). [ND: Not determined]. 


\section{SUPPLEMENTARY DATA REFERENCES}

[1] Jinek, M., Chylinski, K., Fonfara, I., Hauer, M., Doudna, J. A., and Charpentier, E. (2012) A programmable dual-RNA-guided DNA endonuclease in adaptive bacterial immunity. Science 337, 816-821.

[2] Beckert, B., and Masquida, B. (2011) Synthesis of RNA by in vitro transcription. Methods Mol. Biol. 703, 29-41.

[3] Nahvi, A., and Green, R. (2013) Structural analysis of RNA backbone using in-line probing. Methods Enzymol. 530, 381-397.

[4] Bachman, J. (2013) Site-directed mutagenesis. Methods Enzymol. 529, 241-248.

[5] Scholz, J., Besir, H., Strasser, C., and Suppmann, S. (2013) A new method to customize protein expression vectors for fast, efficient and background free parallel cloning. $B M C$ Biotechnol. 13, 12.

[6] Edelheit, O., Hanukoglu, A., and Hanukoglu, I. (2009) Simple and efficient site-directed mutagenesis using two single-primer reactions in parallel to generate mutants for protein structure-function studies. BMC Biotechnol. 9, 61.

[7] Gibson, D. G., Young, L., Chuang, R. Y., Venter, J. C., Hutchison, C. A., 3rd, and Smith, H. O. (2009) Enzymatic assembly of DNA molecules up to several hundred kilobases. Nat. Methods 6, 343-345.

[8] Bolukbasi, M. F., Gupta, A., Oikemus, S., Derr, A. G., Garber, M., Brodsky, M. H., Zhu, L. J., and Wolfe, S. A. (2015) DNA-binding-domain fusions enhance the targeting range and precision of Cas9. Nat. Methods 12, 1150-1156.

[9] Amrani, N., Gao, X. D., Liu, P. P., Edraki, A., Mir, A., Ibraheim, R., Gupta, A., Sasaki, K. E., Wu, T., Donohoue, P. D., Settle, A. H., Lied, A. M., McGovern, K., Fuller, C. K., Cameron, P., Fazzio, T. G., Zhu, L. J., Wolfe, S. A., and Sontheimer, E. J. (2018) NmeCas9 is an intrinsically high-fidelity genome-editing platform. Genome Biol 19. 